\title{
Isolated Grauer's gorilla populations differ in diet and gut
}

4 Alice Michel ${ }^{1,2}$, Riana Minocher ${ }^{1,7}$, Peter Niehoff ${ }^{1}$, Yuhong $\mathrm{Li}^{1,8}$, Kevin Nota ${ }^{3}$, Maya A. Gadhvi ${ }^{1}$,

5 Jiancheng $\mathrm{Su}^{1}$, Neetha Iyer ${ }^{2}$, Amy Porter $^{2}$, Urbain Ngobobo-As-Ibungu ${ }^{4}$, Escobar Binyinyi ${ }^{4}$, Radar

6 Nishuli Pekeyake ${ }^{5}$, Laura Parducci ${ }^{3,9}$, Damien Caillaud ${ }^{2}$, Katerina Guschanski ${ }^{1,6}$

$8{ }^{1}$ Animal Ecology, Department of Ecology and Genetics, Evolutionary Biology Centrum, Uppsala

9 University, Sweden

$10 \quad{ }^{2}$ Department of Anthropology, University of California, Davis, CA, USA

$11{ }^{3}$ Plant Ecology, Department of Ecology and Genetics, Evolutionary Biology Centrum, Uppsala

12 University, Sweden

$13{ }^{4}$ The Dian Fossey Gorilla Fund International, Kinshasa, DRC

$14{ }^{5}$ Institut Congolais pour la Conservation de la Nature, Kinshasa, DRC

$15{ }^{6}$ Institute of Evolutionary Biology, School of Biological Sciences, University of Edinburgh, UK

$16{ }^{7}$ Department of Human Behaviour, Ecology and Culture, Max-Planck Institute for Evolutionary

17 Anthropology, Leipzig, Germany

$18{ }^{8}$ Conservation Ecology Group, Groningen Institute for Evolutionary Life Sciences, University of

19 Groningen, The Netherlands

$20{ }^{9}$ Department of Environmental Biology, Sapienza University of Rome, 00185 Rome, Italy

Short running title: Diet and gut microbiome of Grauer's gorillas

24 Correspondence:

25 Alice Michel: aljmichel@ucdavis.edu; Katerina Guschanski: katerina.guschanski@ed.ac.uk

27 Keywords: Metabarcoding, 16s rRNA, $\operatorname{trn} \mathrm{L}$, critically endangered, genetic diversity, faecal DNA 


\section{Abstract}

29 Conservation efforts tend to focus on populations that are genetically differentiated without paying

30 attention to their ecological differentiation. However, isolated populations may be ecologically unique,

31 an important aspect for the design of appropriate conservation measures for endangered species. Here

32 we investigate the interplay between diet and gut microbiome in several geographically isolated and genetically differentiated populations of the critically endangered Grauer's gorilla. We find that dietary and gut microbial profiles are population-specific, likely due to geographic isolation and environmental differences. In addition, social groups within each population also differed in diet and, to a lesser extent, in gut microbial composition and diversity. Individuals at low elevation consumed a larger variety of

37 plant taxa than those at high elevation, consistent with the notion that dietary choice is constrained by food availability that changes with elevation. Despite no detectable correlation between the diet and gut microbiome in richness or evenness, dietary and gut microbial composition covaried significantly. As we did not find evidence for an effect of genetic relatedness on the composition of the gut microbiome of Grauer's gorillas, this pattern is likely a result of long-term social, ecological, and geographic factors acting on both diet and microbiome. These results reveal that isolated and genetically distinct populations of Grauer's gorillas are also ecologically distinct, highlighting the need to dedicate separate conservation efforts for each population. 


\section{Introduction}

Biodiversity world-wide is declining rapidly due to habitat loss, overexploitation, and climate change (Ceballos et al., 2020; Haddad et al., 2015; IUCN, 2021; Ripple et al., 2019). The aim of conservation is to prevent this decline and to preserve unique species and populations (DeWoody et al., 2021; Teixeira \& Huber, 2021). Across a species' range, variation in environmental conditions combined with restricted gene flow can lead to population differentiation, due to both neutral (drift) and adaptive (selection) processes. From a conservation perspective, such differentiated populations are important, as they contain unique traits that could be lost from the species' pool of variation if the individual populations were to disappear (Cadotte et al., 2011). Therefore, effective conservation requires investigating the ecology and genetics of populations. This necessitates a holistic approach. Non-invasive faecal sampling is a powerful tool for genetic studies of elusive animals (BejaPereira et al., 2009; Schwartz et al., 2007). In addition to DNA from the individual itself, faecal DNA also contains clues to its ecology, including diet and gut microbiome (Valentini et al., 2009). Food consumed reflects individual feeding behaviour and health, and can be informative about foraging strategies, ranging patterns, and social and cultural behaviour (Kamil et al., 2012). Further, diet can reflect local adaptation, if populations specialise due to local availability of different foods or different foraging behaviours and cultures (Alberdi et al., 2020).

Tightly linked to diet, the gut microbiome impacts long-term health and behaviour of its host, by aiding digestion, modulating dietary choice, and stimulating the immune system (Agranyoni et al., 2021; Colston \& Jackson, 2016; Davidson et al., 2020; Ley et al., 2008; Moran et al., 2019). Isolated populations in different habitats have been shown to possess unique gut microbiomes, which is likely a result of ecological and genetic differences (Bueno de Mesquita et al., 2021; Couch et al., 2020; Fietz et al., 2018). The gut microbiome may even facilitate local adaptation and drive genomic evolution (Alberdi et al., 2016; Rudman et al., 2019). It is therefore important to consider gut microbiome when evaluating conservation needs and values (Trevelline et al., 2019; West et al., 2019).

Here, we jointly investigate dietary and gut microbial diversity and composition in isolated and genetically differentiated populations of Grauer's gorillas (Gorilla beringei graueri) using DNA metabarcoding. This gorilla subspecies is endemic to the eastern Democratic Republic of Congo (DRC) 
73 and is classified as critically endangered due to recent drastic population decline (IUCN, 2016; Plumptre

74 et al., 2016, 2021). Our study populations occupy the low and high altitudinal extremes of the species'

75 range $(600-700 \mathrm{~m}, 800 \mathrm{~m}$ and $2100-2400 \mathrm{~m})$, with limited connectivity and gene flow between

76 populations (Baas et al., 2018; Plumptre et al., 2021). We hypothesized that ecological differences

77 would cause diet and gut microbiome to differ between these isolated populations, co-varying with host

78 genetic differentiation. In addition, we investigated whether the taxonomic composition of the gut

79 microbiome is influenced by the dietary profile and examined microbiome stability in individuals

80 through time. 
Materials and Methods

82

Ethics Statement

84

This study was conducted in compliance with legal requirements of the DRC and the animal use policies of UC Davis. Data collection protocols were approved by Institut Congolais pour la Conservation de la

Nature. Samples were collected non-invasively, without approaching or disturbing wild animals.

Sample collection

90

Faecal samples $(\mathrm{n}=220)$ were opportunistically collected from night nests of Grauer's gorillas in eastern DRC between 2015 and 2018 at three sites: Kahuzi-Biega National Park $\left(2.32^{\circ} \mathrm{S}, 28.72^{\circ} \mathrm{E}\right.$; KBNP; $2500 \mathrm{~m}$ above sea level [asl]), Nkuba Conservation Area in Walikale territory, North Kivu $\left(1.38^{\circ} \mathrm{S}, 27.47^{\circ} \mathrm{E}\right.$; NCA; $600 \mathrm{~m}$ asl), and Maiko National Park $\left(0.87^{\circ} \mathrm{S}, 27.35^{\circ} \mathrm{E}\right.$; MNP; $830 \mathrm{~m}$ asl;

Figure 1). In KBNP, gorillas in the Chimanuka group were habituated to human presence and samples were collected from identified individuals immediately upon defecation. All other samples were collected from night nests without knowledge of individual identity following the two-step collection method (Nsubuga et al., 2004). Geographic location and altitude were recorded using handheld GPS for all sampling sites except for the Mankoto group in KBNP, for which this information is missing. We assigned age classes in the field based on dung diameter, as follows: infant $<4 \mathrm{~cm}$, sharing a nest with an adult; juvenile/subadult $<5 \mathrm{~cm}$, own nest; and adults $>5 \mathrm{~cm}$ (McNeilage et al., 2006; Schaller, 1963). For the Chimanuka group, age classes of identified individuals were known from observations. We included biological replicates for several individuals for genotyping and gut microbiome analyses.

DNA extraction 
in a dedicated primate faecal extraction laboratory. We implemented the following modifications to the

110 manufacturer's protocol: faecal samples were incubated under shaking (500 RPM) in the C1 solution

111 overnight at $23^{\circ} \mathrm{C}$. They were then transferred into a heating block and incubated at $65^{\circ} \mathrm{C}$ for 10 minutes,

112 followed by bead beating on a vortex at maximum speed for 1 hour. Incubation in C2 and C3 solution

113 was on ice. We incubated the samples in C6 solution at room temperature for 5 minutes before elution.

Gorilla genotyping, individual identification, relatedness and population differentiation analyses

We genotyped all 220 samples at 12 microsatellite loci (vWF, D1s550, D4s1627, D5s1457, absence of contamination in blanks. Up to four loci were pooled, based on fluorophores and product sizes, and run on the ABI GeneAnalyzer (ThermoFisher Scientific). We scored genotypes manually in GeneMapper v5.0 (Chatterji \& Pachter, 2006) and used Cervus v3.0.7 (Kalinowski et al., 2007) to identify individuals. Samples were considered from the same individual if their genotypes had no mismatches and matched at five or more loci, with the probability of identity assuming full-sibling relationship (PIDsib) less than 0.05 . We manually generated consensus individual genotypes from matching samples, taking into account their time and place of sample collection, and evidence about the presence of other individuals from the same group.

We tested for deviations from Hardy-Weinberg equilibrium, heterozygote deficiency, and

130 linkage disequilibrium at each locus in GenePop v4.7.5 (Raymond \& Rousset, 1995; Rousset, 2008).

131 Genetic population structure was assessed using STRUCTURE v2.3.4 (Porras-Hurtado et al., 2013) frequencies (Falush et al., 2003). Results from different runs of K were merged in CLUMPP (Jakobsson \& Rosenberg, 2007; Kopelman et al., 2015), and analysed and visualized in 'pophelper' in R (Francis, 
137 We used the 'adegenet' R package for Principle Component Analysis (PCA) based on individual

138 genotypes (Jombart, 2008). Population differentiation statistics F $_{\text {ST }}$ and F'sT (Meirmans \& Hedrick,

139 2011) were calculated in GenoDive v3.04 (Meirmans, 2020), and significance assessed with 9999

140 permutations. We compared genetic relatedness between populations and social groups using an

141 AMOVA in the R package 'poppr' (Kamvar et al., 2014) and calculated pairwise relatedness $(r)$

142 between all individuals within KBNP and NCA separately in ML-Relate (Kalinowski et al., 2006).

144 Characterization of gorilla diet

We characterized the diet of 92 unique individuals identified by genotyping (see Results), from

147 nine social groups and two lone silverbacks (Table S1, S2). Where possible, we selected a single nest site per group, to maximize the number of unique individuals. When multiple samples per individual were available, we chose the sample that performed best in genotyping as indication of quality. been successfully used for dietary metabarcoding in primates, and for which a large database of tropical plants is available (Mallott, Garber, et al., 2018). We used the standard $\operatorname{trn} \mathrm{L} g$ and $\mathrm{h}$ primers (Table S3), tagged with 96 eight-base-pair (bp) barcodes. Each barcode differed from all others at a minimum of three positions. DNA amplifications were carried out in $20 \mu 1$ reactions containing $2 \mu 1$ faecal DNA extract, 1 U Platinum II Taq Hot-Start DNA polymerase, 1x Platinum II Buffer, 0.2 mM each dNTP, 2 $\mathrm{mM} \mathrm{MgCl} 2$, and $1 \mu \mathrm{M}$ each primer. Each DNA sample was amplified twice. The duplicates were placed randomly on different PCR plates to avoid potential batch effects and biases due to cross-contamination of sample and/or barcoded primer (Table S1). We included one PCR negative and two to three empty wells per plate, to check for contamination during PCR (Taberlet et al., 2018). In addition, we included five DNA extraction blanks. PCR conditions consisted of 2 minutes denaturation at $94^{\circ} \mathrm{C}$ followed by 35 cycles of $94^{\circ} \mathrm{C}$ for 30 seconds, $51^{\circ} \mathrm{C}$ for 30 seconds, and $68^{\circ} \mathrm{C}$ for 15 seconds, without final extension. PCR products were checked on a $2 \%$ agarose gel to confirm amplification without contamination. 
165 Netherlands), eluting in $50 \mu \mathrm{lEB}$ buffer. Double-indexed next-generation sequencing libraries (Kircher

166 et al., 2012) were prepared as detailed (Brealey et al., 2020; Rohland et al., 2015) but using not-barcoded

167 incomplete adapters after blunt-end repair. Two library preparation blanks were carried through all

168 steps. Each pool was quantified using qPCR with PreHyb primers (Table S3; Rohland et al., 2015) and

169 amplification settings as in Brealey et al. (2020).

170 Each sample pool and both library blanks received a unique combination of indices (Table S1).

171 For indexing PCR, we used the same reaction mixture and cycling conditions as Brealey et al. (2020).

172 The number of cycles ranged from 8 to 10, depending on the copy number estimated from qPCR (Table

173 S1). Library preparation blanks were amplified for 10 cycles to maximize capture of potential

174 contaminants. We performed MinElute purification and quantified indexed pools with qPCR, as above,

175 using $i 7$ and i5 primers (Rohland et al., 2015, Table S3). Indexed sample pools were combined in

176 equimolar amounts, except for library preparation blanks, of which we added $0.5 \mu 1$ each into the final

177 pool, corresponding to the lowest amount added for any sample. The final sequencing pool was cleaned

178 using AmPure XP beads (Beckman Coulter, USA) with two elutions (0.5x followed by 1.8x), which

179 remove very large fragments and fragments $<100 \mathrm{bp}$, respectively. This size selection is optimized for

180 the retention of $\operatorname{trn} \mathrm{L}$ amplicons $(\sim 10-150 \mathrm{bp}$ in length $+148 \mathrm{bp}$ of barcoded and indexed adapters).

181 Elution was performed in $30 \mu \mathrm{l}$ of EB buffer. The cleaned library pool was quantified using both a

182 Qubit High Sensitivity fluorometer and 2200 TapeStation and sequenced at the Uppsala Science for

183 Life Laboratory on a single MiSeq lane with 150 bp paired-end sequencing with version 2 chemistry.

Sequence processing and analysis was done in OBITools v1.2.13 (Boyer et al., 2016). Paired reads with quality scores $>40$ and overlap $>10$ bp were retained and merged. Sample of origin for each read was established through its index and barcode, requiring an exact sequence match. Sequences were

187 clustered into molecular operational taxonomic units (MOTUs), each representing a unique plant taxon

188 (Valentini et al., 2009). A large number of MOTUs had fewer than 10 sequences across all samples and were removed as recommended (e.g., Shehzad et al., 2012). We also removed sequences that differed by exactly one nucleotide from a more abundant sequence and had a total count less than $5 \%$ of the more abundant sequence, following Boyer et al. (2016). 
193 frequency plot of identity to the reference database (Figure S1) and similar trnL-based studies of

194 tropical primate diet (e.g., Quéméré et al., 2013), we removed sequences below an identity threshold

195 of 0.90. Below this, sequences were regarded as likely chimeric, enriched in sequencing or PCR

196 errors. No singletons were present after this filtering step.

197

Compiling plant $\operatorname{trn} L$ reference database

199

We built a local DNA barcoding reference library by downloading all 324,502 available sequences from NCBI GenBank using the search query: "(trnL[All Fields] OR complete genome[All from NCBI (ftp://ftp.ncbi.nih.gov/pub/taxonomy/taxdump.tar.gz, last accessed 3 December 2021). To complete the database of $\operatorname{trn} \mathrm{L}$ genes, we followed established protocol (Boyer et al., 2016), using the same $\operatorname{trn} \mathrm{L} \mathrm{g}$-h primers as in the wet laboratory to extract $\operatorname{trn} \mathrm{L}$ variants in silico in the program ecoPCR amplicons, in 608 families and 5,662 genera. compared plant taxa present in our database to a list of plants known to occur in the Kahuzi and Itebero

212 regions of KBNP (Yumoto et al., 1994). To enable this comparison, we updated the taxonomic 213 classification of the KBNP plant list (Yumoto et al., 1994) by searching for species names in the Global

214 Biodiversity Information Facility (GBIF). The updated list contained 328 taxa, in 81 unique families 215 and 234 genera. Of these, all families and $77.4 \%$ of genera were present in our $\operatorname{trn} \mathrm{L}$ database. 
220 KBNP and NCA populations (Table S2). (Samples from MNP were not yet available at the time of microbiome characterization.) The dataset included multiple samples from 15 individuals (2-3 each), collected 0-257 days apart ( mean $=27$ days, median $=0)$, which we used to evaluate intra- versus interindividual variation in microbiome composition. We also carried nine random extraction blanks through the entire data generation process, on par with samples.

The V4 region of the $16 S r R N A$ gene was amplified with primers 515F/806R (Table S3) for each sample in duplicate. The PCR reaction contained $2 \mu 1$ of extracted DNA, $5 \mu \mathrm{M}$ each of the forward and reverse primer, 1x Phusion High-Fidelity Buffer, 0.02 units Phusion HF DNA polymerase $(2 \mathrm{U} / \mu \mathrm{l})$, $0.012 \mathrm{mg}$ DMSO and $0.05 \mu \mathrm{M}$ (each) dNTPs, with the volume made up to $20 \mu 1$ with Ultrapure $\mathrm{H} 2 \mathrm{O}$. Thermal cycling conditions were as follows: 30 seconds at $98^{\circ} \mathrm{C}, 25$ cycles of $98^{\circ} \mathrm{C}$ for 10 seconds, $52^{\circ} \mathrm{C}$ for 20 seconds and $72^{\circ} \mathrm{C}$ for 20 seconds, and 10 minutes at $72^{\circ} \mathrm{C}$. PCR cycles were limited to 25 to minimize the risk of unspecified products and chimeras. Duplicate reactions were pooled and cleaned with AmPure beads (Qiagen).

Next-generation sequencing libraries were prepared from PCR products following the double234 barcoding, double-indexing strategy (Kircher et al., 2012; Meyer \& Kircher, 2010; Rohland et al., 2015; van der Valk et al., 2017). As a result, each sample had a unique combination of two barcodes and two indices, which enabled bioinformatic filtering of potential chimeric molecules and misassigned reads resulting from index hopping (van der Valk et al., 2017, 2020). For indexing, we determined the suitable number of PCR cycles (8-11) based on qPCR of barcoded libraries, as above. Indexed libraries were quantified by qPCR and pooled in equimolar amounts for sequencing on a single MiSeq lane, using version 2 chemistry and 250 bp paired end sequencing at the Uppsala Science for Life Laboratory sequencing facility. using DADA2 (Callahan et al., 2016), rather than clustering sequences, which avoids biases due to arbitrary similarity thresholds (Edgar, 2018). Forward and reverse reads were truncated to 200 and 150

246 bp, respectively, at which point read quality scores dropped below 35 . We merged paired-end reads, 
requiring an overlap of at least $12 \mathrm{bp}$, and removed sequences outside the 250-256 bp range and those with any barcode mismatch, as recommended (Callahan et al., 2016).

250 (Quast et al., 2012). Species-level assignment required a strict 100\% match (Edgar, 2018). We removed singletons and ASVs labelled 'Unassigned', 'Eukaryota', "mitochondria", or "chloroplast". We retained Archaea, although archaeal amplification from the V4 region of the $16 S r R N A$ is limited (Raymann et al., 2017), because within-dataset comparisons are nonetheless informative. We built a bacterial phylogenetic tree by aligning sequences to the Greengenes 13 _5 mega-phylogeny $(203,452$ 99\% OTUs; DeSantis et al., 2006) in SEPP using default parameters (Mirarab et al., 2012).

To examine dietary and microbiome diversity, we analysed the $\operatorname{trn} \mathrm{L}$ and $16 S \operatorname{rRNA}$ metabarcoding datasets, after first filtering out rare sequence variants below $0.5 \%$ relative abundance in at least one sample, as suggested (Deagle et al., 2019). We evaluated sampling effort and sequencing depth accumulation curves in the R packages 'vegan' (Oksanen et al., 2020) and 'ranacapa' (Kandlikar et al., 2018), respectively. We checked whether the predicted number of taxa (asymptote of the sequencing accumulation curve) minus actual number of taxa (richness) related to any of the considered biological variables or sequencing depth (read count) using a generalised linear model (GLM) with quasi-Poisson error distribution in the R package 'lme4' (Bates et al., 2015). Shannon's diversity index, or evenness (Chao et al., 2014). As recommended by McMurdie \& Holmes (2013), we did not rarefy to minimum sequencing depth. To test the effects of population, social group, altitude, sex, and age class on diversity metrics, we fitted a GLM with quasi-Poisson (for richness) or difference (HSD) post-hoc comparisons between levels of categorical variables that were overall significant $\left(\chi^{2}\right.$ test with Bonferroni correction) (Lenth et al., 2021). 
275 designed for the compositional nature of metabarcoding data (Gloor et al., 2017; Weiss et al., 2017).

276 We used Bayesian multiplicative zero replacement and then centred and log-ratio (CLR) transformed

277 each dataset using the R packages 'zcompositions' (Palarea-Albaladejo \& Martín-Fernández, 2015) and

278 'compositions' (van den Boogaart \& Tolosana-Delgado, 2008). For the microbiome dataset, we secondarily used Phylogenetic Isometric Log-Ratio Transform (phILR) to compute compositional abundance at phylogenetic balances (Silverman et al., 2017). To evaluate variation in composition of diet and microbiome, we computed Aitchison's dissimilarity (Euclidean distance between CLR values) (Aitchison et al., 2000). To quantitatively estimate which factors best predict variation in diet and gut microbiome, we modelled the composition in CLR (or phILR) transformed space as a function of ecological and biological variables using PERMANOVA, via function adonis2 in 'vegan' (Anderson \& Walsh, 2013). The predictor variables were population, social group, sex, age class, and altitude. Sequencing read count was kept as the first predictor, even if $\mathrm{p}>0.05$. Post-hoc comparisons between levels of overall significant variables were done with Bonferroni correction using 'pairwiseAdonis' (Arbizu, 2020). We assessed the temporal stability of individual microbiomes using a pairwise genetic distance ( 1 - genetic relatedness) was modelled separately within each population using Mantel and partial Mantel tests (controlling for social group identity).

We estimated the covariance between diet and microbiome using a co-inertia analysis between the two matrices in the package 'omicade4' and calculated the RV coefficient (Escoufier, 1973; Robert

294 \& Escoufier, 1976) and its significance using a Monte Carlo test with 999 permutations (Meng et al., 295 2014). To compare the effects of diet and other variables on the gut microbiome, we fit a Multiple 296 Regression on Matrices (MRM) model (Lichstein, 2007), an extension of the partial Mantel test, in 297 'ecodist' (Goslee \& Urban, 2007). The explanatory variables were straight-line geographic distance, altitude difference, diet composition (Aitchison distance), and social group and population as binary

299 (same, 0, or different, 1). Significance was assessed using 999 permutations of the response variable,

300 the Aitchison distance matrix of gut microbiome composition. 
302 subtle differences across an entire community. To identify dietary and microbial taxa that may have

303 driven compositional differences, we used the R package 'ALDEx2' and focused on significant

304 differences (Wilcoxon rank sum test with correction for false discovery rate (FDR) $p<0.05$ ) with effect

305 sizes $>1$, as recommended (Gloor et al., 2017).

306 
bioRxiv preprint doi: https://doi.org/10.1101/2022.01.04.474987; this version posted January $5,2022$. The copyright holder for this preprint (which was not certified by peer review) is the author/funder, who has granted bioRxiv a license to display the preprint in perpetuity. It is made available under aCC-BY-NC-ND 4.0 International license.

Results

Study populations of Grauer's gorillas are genetically differentiated

We identified 92 unique individuals in the three study populations by microsatellite genotyping:

31259 in KBNP, 28 in NCA, and 5 in MNP (Figure 1A, Table S2). Individuals belonged to six different

313 social groups in KBNP, two in NCA, and one in MNP. We sampled four to 17 individuals from each

314 social group. In addition, there were two solitary adult male gorillas (lone silverbacks) in KBNP.

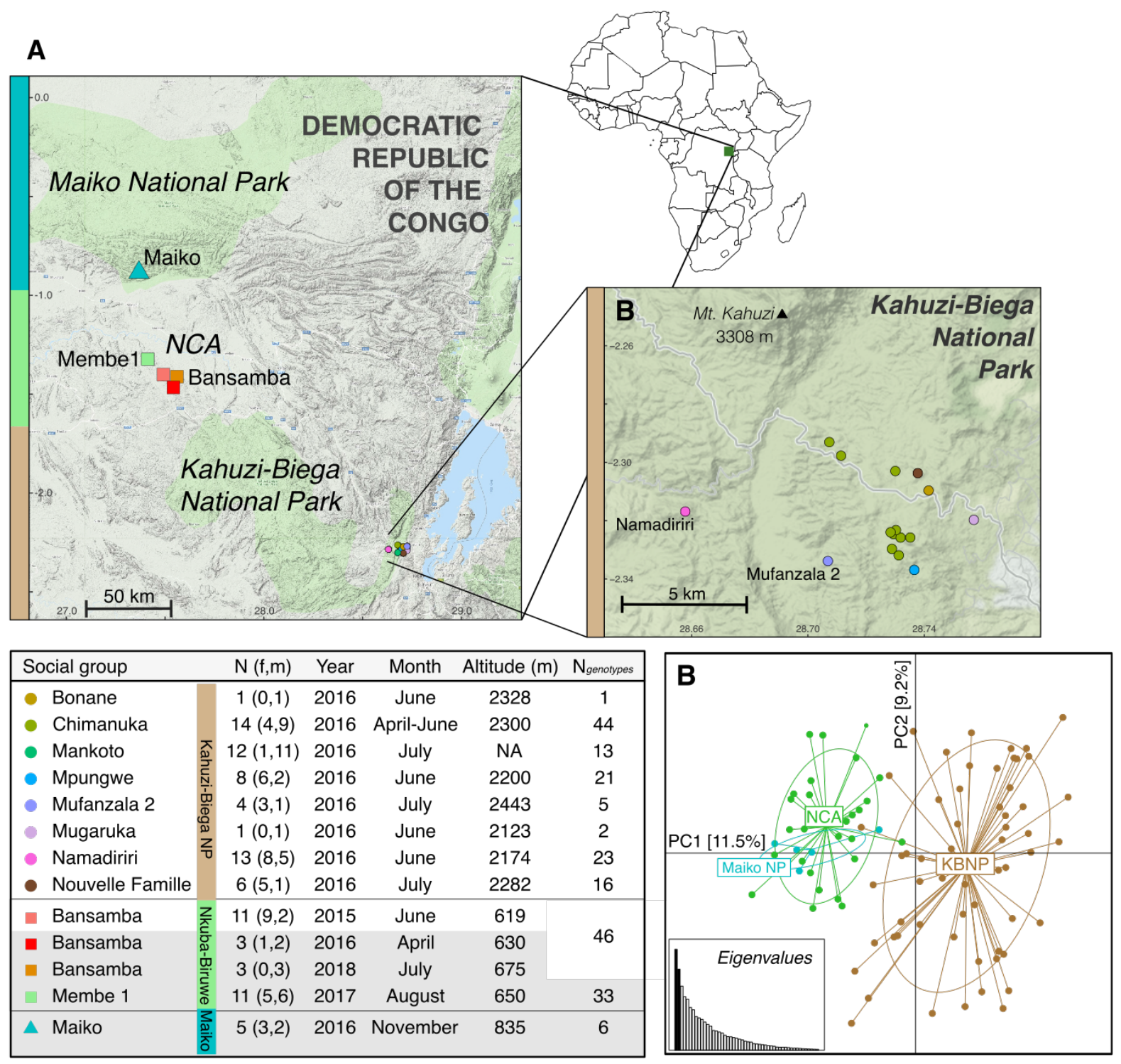

Figure 1. Geographic location and genetic differentiation of Grauer's gorilla populations. (A) Broad geographic location of Grauer's gorilla populations in Maiko National Park (MNP; designated with cyan on the left-hand side of the map), Nkuba Conservation Area (NCA; green) and Kahuzi-Biega National Park (KBNP; brown). Multiple social groups were collected in NCA and KBNP. Each social group is given its own symbol colour, whereas repeated sampling of the same social group is shown by multiple identical or, for the group sampled in multiple years, similarly coloured symbols. The inset (B) zooms in on KBNP. Circle colours designate 
different social groups, as shown in the table (C). Note that multiple circles are present for the Chimanuka group, consistent with repeated, opportunistic sampling of identified individuals. Geographic coordinates were not available for Mankoto group. (C) Overview of sample size for dietary characterization ( $\mathrm{N}=$ number of unique individuals), sex composition ( $\mathrm{f}=$ number of females, $\mathrm{m}=$ number of males), collection year and month, altitude and the total number of successfully genotyped samples from each group. Gut microbiome data is not available for groups shaded in grey. Group Bansamba (NCA) was sampled repeatedly, but only few samples were included in dietary analyses in later years ( 3 in 2016 and 3 in 2018). (D) PCA of genetic distances among individuals, coloured by population. KBNP is clearly separated from NCA and MNP.

None of the 12 microsatellite loci deviated from Hardy-Weinberg equilibrium after Bonferroni correction for multiple testing $(p>0.1)$. On average, there were 6.1 alleles per locus. The average observed and expected heterozygosities were 0.66 and 0.68 , respectively. The test for global heterozygote deficiency was not significant overall $(p=0.6)$ or in any population $(p>0.4)$. The test for genotypic linkage disequilibrium using log likelihood ratio statistic with 66 pairwise comparisons between the 12 loci was not significant for any pair $(p>0.1)$. Thus, we assumed linkage equilibrium and considered all loci in further analyses.

Analysis of the three populations using STRUCTURE (Porras-Hurtado et al., 2013) revealed two distinct genetic groups (optimal $\mathrm{K}=2$ according to $\Delta \mathrm{K}$; Evanno et al., 2005; Figure S2). The clusters differentiated gorillas in high-altitude KBNP from those in low-altitude NCA and MNP (Figure S3).

Only three KBNP individuals (from two different social groups) showed a higher genetic similarity to the low altitude populations. This population structure was consistent with the PCA, which divides gorilla genotypes in KBNP from NCA and MNP (Figure 1B). All three populations were significantly differentiated from one another $(p<0.001)$, with largest differences between MNP and $\mathrm{KBNP}\left(\mathrm{F}_{\mathrm{ST}}^{\prime}=\right.$ 0.45; Table S4A), which are furthest apart geographically $(215 \mathrm{~km})$. Individuals within social groups were more closely related than individuals in different groups in the same population (AMOVA $\phi=$ 0.12, $p<0.001$; Table S4B), consistent with gorilla social structure (Harcourt \& Stewart, 2013).

\section{Negative controls in $\operatorname{trn} L$ and $16 \mathrm{~S}$ rRNA metabarcoding}

Metagenomic studies rarely report treatment of negative control samples, although stringent quantification of contamination is of utmost importance for any molecular study. To quantify contamination in the diet $(\operatorname{trn} \mathrm{L})$ dataset, we included and analysed five DNA extraction blanks, two 
PCR negative controls, five unused barcode combinations, all sequenced in duplicates, and two library preparation negative controls (Table S2; Table S5). There were $286 \operatorname{trn} \mathrm{L}$ reads belonging to 19 different taxa in the negative controls in total. With two exceptions, the detected taxa showed very low abundance in the blanks (1-3 reads) but were highly abundant in the samples (average $>200,000$ reads). This pattern is consistent with low-level cross-contamination from high quantity into low quantity samples typical for large-scale sequencing studies (Eisenhofer et al., 2019). The two exceptions with high abundance in blanks ( $77 \%$ and $15 \%$ of all blank reads, respectively) had low abundance in the samples $(<0.01 \%)$ and were in the families Fagaceae (chestnut) and Rutaceae (citrus). We thus concluded that they may derive from reagent contamination. Both taxa were automatically removed from the dataset during abundance-based filtering, as they were below the specified $0.5 \%$ cut-off. Zero reads were identified with unused barcode combinations, suggesting that cross-contamination of barcodes during PCR and library preparation was negligible (Taberlet et al., 2018). contained zero reads. The remaining four blanks had six to 72 reads each, in ten different $16 S$ ASVs

(Table S6). These ten taxa were among the most abundant in the samples and thus, as above, likely represent cases of low-level cross-contamination. We found no indication of ASVs exclusive to the blanks, and hence all ASVs were retained in the dataset.

\section{Diet of Grauer's gorillas} locus. After data filtering, we retained 536,160 trnL sequencing reads, $45 \%$ of raw reads, belonging to 120 unique taxa (Table S7A). PCR duplicates were more similar to each other than to other samples in alpha and beta diversity ( $p<0.001$, Figure S4), and hence their sequencing data were pooled. Sample accumulation curves suggested that additional samples would uncover only few novel $\operatorname{trn} \mathrm{L}$ variants could have potentially uncovered novel taxa (Figure S5B), sequencing depth did not have a strong

382 effect on $\operatorname{trn} \mathrm{L}$ richness (three additional taxa per 47,000 reads, $p=0.03$ ). Furthermore, the discrepancy 
per sample in observed minus predicted richness did not corelate with sequencing depth $(p=0.3$, nor

384 with any of the tested variables (population $p=0.9$; social group $p=0.06$; sex $p=0.6$; age class $p=$

3850.8 ; altitude $p=0.4$ ). Taken together, this suggests that our dataset is suitable to carry out comparisons

386 across study populations.

Of the 120 detected taxa, 115 could be identified to at least the order level (in 29 different orders), 110 to family (in 49 families), and 44 to genus (in 35 genera) (Table S8). Based on previous studies of Grauer's gorilla diet in KBNP, NCA, and Mt. Tshiaberimu (Kambale, 2018; van der Hoek, Pazo, et al., 2021; Yamagiwa et al., 1994, 2005; Yumoto et al., 1994) and plant distribution in the region

391 (Spira et al., 2018), we manually confirmed that all taxa assignments were possible. This revealed 21

392 taxa that have not been previously reported to be consumed by gorillas but occur in the study region

(Table S8).

2A). The most abundant taxon across the dataset was Urera sp. (MOTU1, 25.6\% of all reads), followed by Apocynaceae sp. (MOTU2, 14.8\%), Apocynoideae sp. (MOTU5, 6.7\%), Urticaceae sp. (MOTU6,
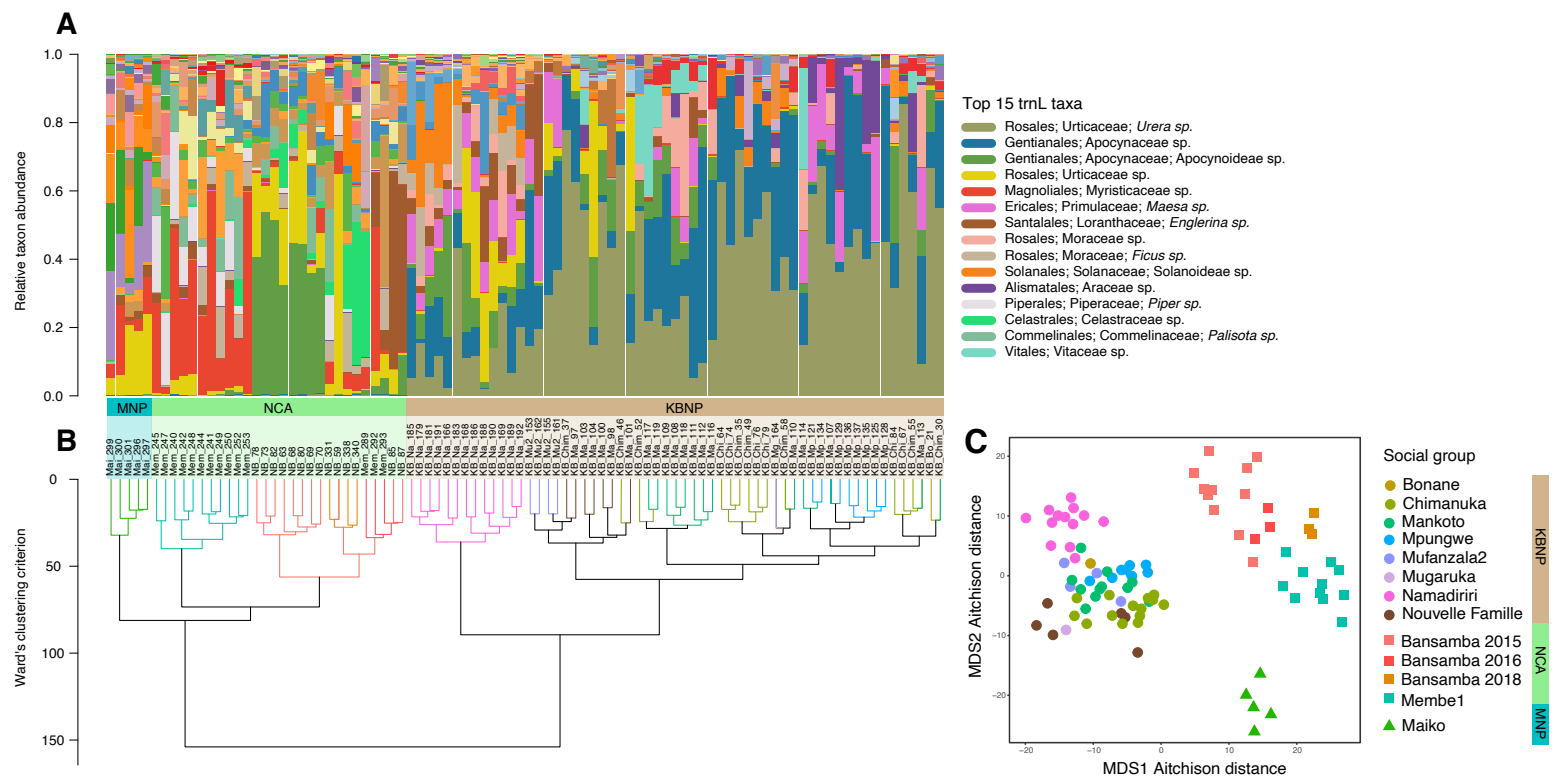
(Maiko NP cyan, Nkuba Conservation Area green, Kahuzi-Biega NP brown). (B) Hierarchical cluster dendrogram of Ward's sum of squares based on minimum variance of squared dissimilarities (Murtagh \& Legendre, 2014) of centred-log-ratio (CLR) transformed taxon abundance. Relative taxon abundance clustered by population (aligned to the bars below (A)) and by social group, shown as coloured tips in the dendrogram (see legend to right of (C)). (C) Non-metric multidimensional scaling (NMDS) ordination of trnL CLR-transformed Aitchison distances, representing dietary composition dissimilarity across KBNP, NCA, and MNP. Groupings by population (shape) and social group (colours) were significant (PERMANOVA $\mathrm{p}<0.001, \mathrm{R}^{2}=0.28,0.22$, respectively).

Geography, altitude and social group identity influence dietary diversity and composition in Grauer's gorillas $<0.001$, Table S9). Both richness and evenness were higher in low altitude populations (NCA and MNP) than in high-altitude KBNP (mean richness: 66.8 taxa in MNP, 65.6 in NCA vs. 54.5 in KBNP, evenness: 10.0 in MNP, 8.4 in NCA, vs. 5.4 in KBNP, $p<0.001$; Figure S6). Within the KBNP population, the diets of social groups Namadiriri and Nouvelle Famille were richer than other groups

Table S9; Figure S6). One of these groups, Namadiriri, was sampled at lower elevation than any other social group in KBNP. In this population, one standard deviation of altitudinal increase $(84 \mathrm{~m})$ from the mean $(2250 \mathrm{~m}$ asl) corresponded in a $6 \%$ decrease in richness and $25 \%$ decrease in dietary evenness $(p$ $<0.001$; Figure S7). In contrast, neither individual's sex nor age class (age class available for N=70) had an effect on dietary richness or evenness $(p>0.3)$. social group. NMDS ordination showed a similar pattern (Figure 2C). After accounting for slight differences in sequencing depth, dietary composition was significantly influenced by population $(p<$ $0.001)$, which explained $27.9 \%$ of the variance, and social group $(p<0.001)$, which explained an additional 21.6\%, but not sex $(p=0.7)$ nor age class $(p=0.2$; Table 1). All between-group post-hoc comparisons were significant $(p<0.05)$, suggesting that the group Chimanuka was not an outlier, 
bioRxiv preprint doi: https://doi.org/10.1101/2022.01.04.474987; this version posted January 5,2022 . The copyright holder for this preprint (which was not certified by peer review) is the author/funder, who has granted bioRxiv a license to display the preprint in perpetuity. It is made available under aCC-BY-NC-ND 4.0 International license.

Table 1. PERMANOVA model of factors influencing dietary composition

\begin{tabular}{|c|c|c|c|c|c|c|c|}
\hline \multirow{2}{*}{ Variable } & \multirow{2}{*}{ Df } & \multirow{2}{*}{$\mathbf{R}^{2}$} & \multirow{2}{*}{$\mathbf{F}$} & \multirow{2}{*}{$p$} & & \multicolumn{2}{|l|}{ Post-hoc tests } \\
\hline & & & & & & Significant pairwise comparisons & p Ponferroni $_{1}$ \\
\hline \multirow[t]{2}{*}{ Read Count } & 1 & 0.01 & 1.73 & 0.05 & & - & \\
\hline & & & & & & $\mathrm{NCA}-\mathrm{KBNP}$ & $<0.001$ \\
\hline \multirow[t]{3}{*}{ Population } & 2 & 0.279 & 17.80 & $<0.001$ & & KBNP - MNP & $<0.001$ \\
\hline & & & & & & MNP - NCA & $<0.001$ \\
\hline & & & & & \multirow{13}{*}{ 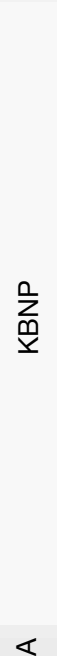 } & Chimanuka - Nouvelle Famille & 0.02 \\
\hline \multirow[t]{13}{*}{ Social Group } & 6 & 0.216 & 4.56 & $<0.001$ & & Chimanuka - Mankoto & 0.005 \\
\hline & & & & & & Chimanuka - Mpungwe & 0.005 \\
\hline & & & & & & Chimanuka - Mufanzala2 & 0.02 \\
\hline & & & & & & Chimanuka - Namadiriri & 0.005 \\
\hline & & & & & & Nouvelle Famille - Mankoto & 0.02 \\
\hline & & & & & & Nouvelle Famille - Mpungwe & 0.02 \\
\hline & & & & & & Nouvelle Famille - Namadiriri & 0.005 \\
\hline & & & & & & Mankoto - Mpungwe & 0.005 \\
\hline & & & & & & Mankoto - Mufanzala2 & 0.03 \\
\hline & & & & & & Mankoto - Namadiriri & 0.005 \\
\hline & & & & & & Mpungwe - Namadiriri & 0.005 \\
\hline & & & & & & Mufanzala2 - Namadiriri & 0.02 \\
\hline & & & & & ర্ঠ & Membe1 - Bansamba & 0.005 \\
\hline Sex & 1 & 0.005 & 0.82 & 0.6 & & - & \\
\hline Age class $\dagger$ & 2 & 0.022 & 1.28 & 0.1 & & - & \\
\hline
\end{tabular}

†Age class (Infants $(\mathrm{N}=7)$, Juveniles/subadults $(\mathrm{N}=21)$, Adults $(\mathrm{N}=42)$ ) was modelled separately using a reduced dataset, since only $70 / 92$ samples had age estimates. In this model the other predictor variables had similar estimates, so for all other variables the model for the complete dataset $(\mathrm{n}=92)$ is presented.

We identified differentially abundant taxa by population and social group using ALDEx2 with FDR < 0.05) and were considered important contributors to population dietary uniqueness (effect

443 size > 1). These were dominated by the family Urticaceae, especially the genus Urera, and also included

444 Piper sp. (Piperaceae), Maesa lanceolata (Primulaceae), and taxa in Apocynaceae and Solanaceae. In

445 NCA, seven taxa including Megaphrynium, Marantochloa, Aframomum, Palisota, and Myristicaceae 446 spp., were enriched relative to the other populations. We found 14 enriched taxa in MNP, notably

447 Apocynaceae spp. Out of the 21 previously undescribed food items, 13 were more common in low448 altitude populations in comparison to the high-altitude population. These taxa included Gnetum sp., 449 more abundant in NCA relative to KBNP and MNP (MOTU34, effect $=0.93$ ) and Humiriaceae sp., enriched in both NCA and MNP relative to KBNP (MOTU48, effect $=0.79)($ Table S8, S9). Within 
bioRxiv preprint doi: https://doi.org/10.1101/2022.01.04.474987; this version posted January 5, 2022. The copyright holder for this preprint (which was not certified by peer review) is the author/funder, who has granted bioRxiv a license to display the preprint in perpetuity. It is made available under aCC-BY-NC-ND 4.0 International license.

$452=8)$.

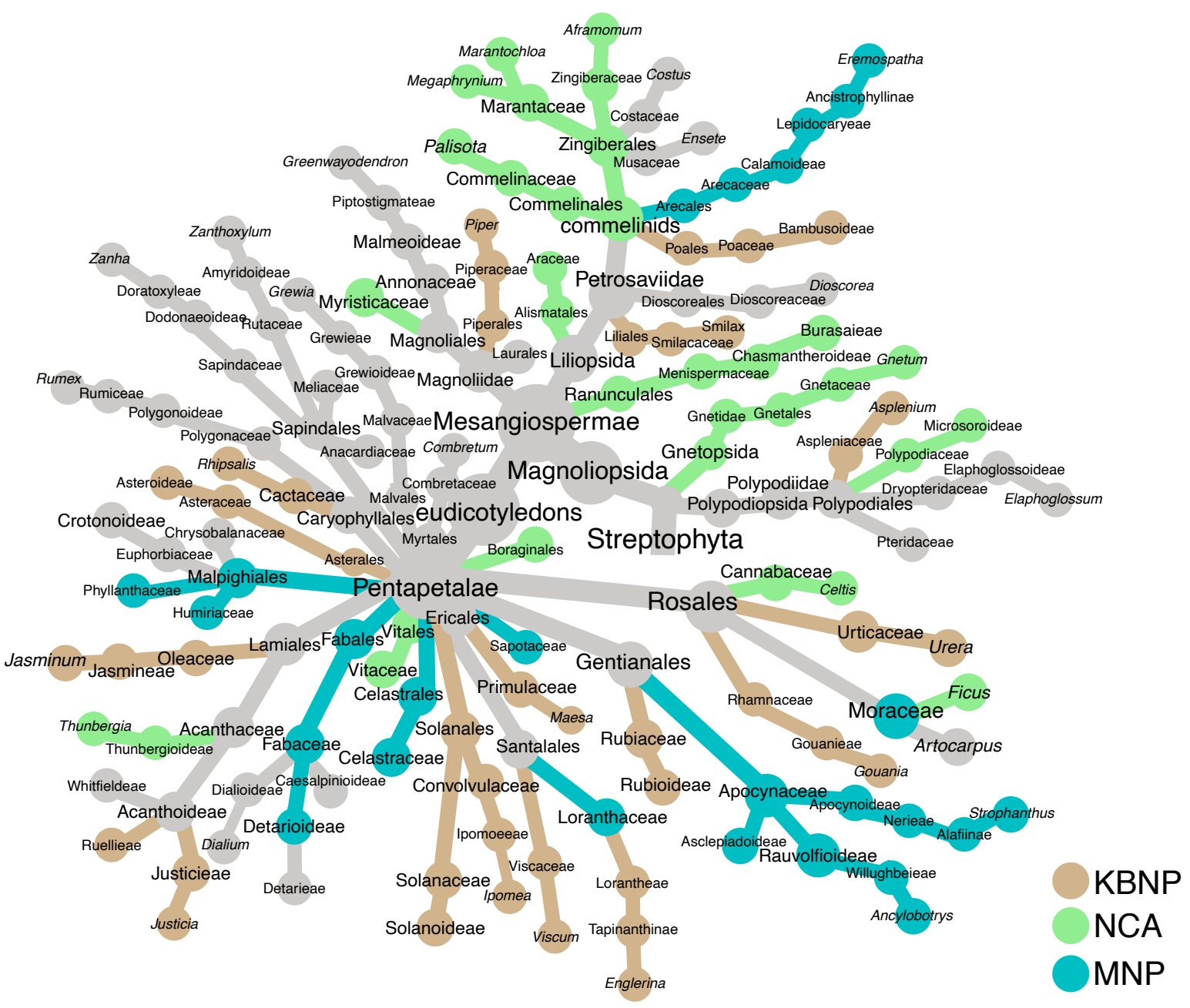

$454 \quad$ Figure 3. Grauer's gorilla diet across three study populations. Differentially abundant taxa are coloured according to the population in which they are significantly more abundant (ALDEx2 Wilcoxon test $p<0.05$ ). For taxa that differ between two or more population pairs, the colour corresponds to the population where the effect size is greatest. Gray taxa do not differ significantly in abundance between populations. Branch lengths do not reflect phylogenetic distance. This diagram was generated with the 'metacoder' package in R (Foster et al., 2017). 

similar in samples from the same individual collected zero to 257 days apart (mean compositional dissimilarity $=35.0$ ) than between different individuals from the same social group sampled zero to 231 days apart (Wilcoxon Test $p<0.001$ ). Therefore, for further analysis we focused on the 68 unique individuals and picked the same faecal samples used for dietary analyses. The final dataset contained 2,965,516 reads in 421 unique microbial taxa (Table S11).

The sample accumulation analyses suggested that additional sampling of faeces from more individuals could uncover novel gut commensals at the population level (Figure S8A). However, per sample sequencing depth was sufficient to obtain a good representation of host microbiome diversity microbiome of Grauer's gorillas. All taxa were identified at least to the family level; 309 taxa were refined further to genus and 17 to species (Table S11). None were closely related to dominant soil microorganisms (Delgado-Baquerizo et al., 2018). There were seven Archaea in our dataset, from the Methanomethylophilaceae and Methanobacteriaceae families. Each faecal sample contained on average $200.29 \pm 19.6$ unique taxa $(\min =160, \max =237)$, each with average abundance $0.2 \% \pm 0.4 \%$. The most abundant taxa were Christensenellaceae R-7 group sp. (3.07\% per sample), Flexilinea sp. (2.97\%), and Faecalibacterium sp. (2.46\%). Eleven taxa were present in every gorilla faecal sample, constituting a "core microbiome" of Grauer's gorillas (Table 2). the phyla Firmicutes (64.7\%), Bacteroidetes (21.0\%), Spirochaetes (3.8\%), Chloroflexi (3.0\%),

485 Proteobacteria (2.9\%), and Actinobacteria (1.9\%) (Figure S9). The most abundant families were 486 Ruminococcaceae (25.1\%), Lachnospiraceae (14.8\%), and Rikenellaceae (13.1\%) (Figure 4A). 
488 Table 2. Grauer's gorilla core microbiome, taxa present in $100 \%$ of samples.

\begin{tabular}{|c|c|c|}
\hline $\begin{array}{l}\text { Core } \\
\text { Microbiome }\end{array}$ & Abundance $\dagger$ & Taxonomy to genus \\
\hline ASV1 & $2.97 \%$ & Bacteria; Chloroflexi; Anaerolineae; Anaerolineales; Anaerolineaceae; Flexilinea \\
\hline ASV3 & $2.41 \%$ & Bacteria; Firmicutes; Clostridia; Clostridiales; Family XIII; AD3011 group \\
\hline ASV6 & $2.13 \%$ & Bacteria; Firmicutes; Erysipelotrichia; Erysipelotrichales; Erysipelotrichaceae; UCG-004 \\
\hline ASV22 & $0.94 \%$ & Bacteria; Bacteroidetes; Bacteroidia; Bacteroidales; Prevotellaceae; Prevotella 7 \\
\hline ASV21 & $0.87 \%$ & Bacteria; Firmicutes; Clostridia; Clostridiales; Ruminococcaceae; UCG-005 \\
\hline ASV31 & $0.85 \%$ & Bacteria; Firmicutes; Clostridia; Clostridiales; Lachnospiraceae; Oribacterium \\
\hline ASV30 & $0.82 \%$ & Bacteria; Proteobacteria; Gammaproteobacteria; Betaproteobacteriales; Burkholderiaceae; Sutterella \\
\hline ASV33 & $0.74 \%$ & Bacteria; Firmicutes; Clostridia; Clostridiales; Ruminococcaceae; Ruminiclostridium 9 \\
\hline ASV59 & $0.41 \%$ & Bacteria; Firmicutes; Clostridia; Clostridiales; Ruminococcaceae; UCG-002 \\
\hline ASV70 & $0.35 \%$ & Bacteria; Actinobacteria; Coriobacteriia; Coriobacteriales; Eggerthellaceae; Senegalimassilia \\
\hline ASV152 & $0.15 \%$ & Bacteria; Bacteroidetes; Bacteroidia; Bacteroidales; Prevotellaceae; NA \\
\hline
\end{tabular}

Diversity and composition of the gut microbiome in Grauer's gorillas correlates with population and social group identity high-elevation population (richness: mean $\mathrm{KBNP}=202.2$ taxa vs. $\mathrm{NCA}=190.2 ; p=0.05$; evenness: 83.7 vs. $74.2, p=0.01)$, though neither diversity metric was related to altitude within $\operatorname{KBNP}(p=0.07$, 0.9; Table S12; Figure S10). Microbial richness did not differ by sex $(p=0.2)$, but females had higher microbial evenness than males ( 85.7 vs. $78.5, p=0.002)$. There were no differences by age class $(p=$ $0.3,0.1)$. In KBNP, as with diet, the gorilla group Namadiriri had the highest microbial richness and evenness (Table S12). Neither gut microbial richness nor evenness were directly related to dietary richness or evenness $(p>0.2)$, but dietary composition, scaled to one-dimension by NMDS, did correlate with richness ( $p=0.002$; Table S12), a result we investigated further in the following section. and NCA) (Figure 4B-D). Population explained 10.5\% of the total variance, and social group in KBNP explained an additional $17.8 \%(p<0.001$; Table 3). Intergroup differences were not only due to

506 Chimanuka group (Table 3). Overall, gut microbiome dissimilarity was largest between individuals of 507 different populations, followed by individuals from different social groups, and individuals sharing a 
social group were least dissimilar (Figure S11). We modelled altitude separately, as it was distinct for

509 each population and social group (Figure 1). It explained $12.7 \%$ of the variance across populations

$510(\mathrm{~N}=56, p<0.001)$ but only $3.8 \%$ in $\operatorname{KBNP}(\mathrm{N}=45, p=0.01)$. Host genetics did not explain variance in

511 gut microbiome composition in KBNP when social group was considered as a factor $(\rho=0.015, \mathrm{p}=$

512 0.3). Despite low sample size, for the one social group in NCA $(\mathrm{N}=11)$, we also found no correlation

513 between gut microbiome and genetic distance $(\rho=-0.080, p=0.7)$. Microbiome composition did not

514 differ by sex or age class ( $p>0.05$, Table 3). Results using phylogeny-informed (phILR) distances

515 were qualitatively similar (Table S13).

We identified 111 taxa that differed significantly in abundance between NCA and KBNP $(p<$

517 0.05), of which 42 had effect size greater than one (Table S14). At the family-level, gorilla gut

518 microbiomes in KBNP had a higher abundance of Muribaculaceae and Erysipelotrichaceae, while gut

519 microbiomes in NCA had more Spirochaetaceae and Christensenellaceae. At a finer phylogenetic level,

520 populations differed in abundance of specific ASVs belonging to common, shared families like

521 Rikenellaceae, Lachnospiraceae, and Ruminococcaceae.

Table 3. PERMANOVA model of factors influencing microbiome composition

\begin{tabular}{|c|c|c|c|c|c|c|}
\hline \multirow{2}{*}{ Variable } & \multirow{2}{*}{ Df } & \multirow{2}{*}{$\mathbf{R}^{2}$} & \multirow{2}{*}{$\mathbf{F}$} & \multirow{2}{*}{$p$} & \multicolumn{2}{|l|}{ Post-hoc tests } \\
\hline & & & & & Significant pairwise comparisons & $p_{\text {Bonferroni }}$ \\
\hline Read Count & 1 & 0.019 & 1.68 & 0.05 & - & \\
\hline Population & 1 & 0.105 & 7.97 & $<0.001$ & KBNP - NCA & $<0.001$ \\
\hline \multirow{8}{*}{ Social Group } & \multirow{8}{*}{5} & \multirow{8}{*}{0.178} & \multirow{8}{*}{2.18} & \multirow{8}{*}{$<0.001$} & Chimanuka - Nouvelle Famille & 0.004 \\
\hline & & & & & Chimanuka - Mankoto & 0.01 \\
\hline & & & & & Chimanuka - Mpungwe & 0.007 \\
\hline & & & & & Chimanuka - Namadiriri & 0.004 \\
\hline & & & & & Nouvelle Famille - Mankoto & 0.02 \\
\hline & & & & & Nouvelle Famille - Namadiriri & 0.01 \\
\hline & & & & & Mankoto - Mpungwe & 0.007 \\
\hline & & & & & Mankoto - Namadiriri & 0.004 \\
\hline Sex & 1 & 0.014 & 1.18 & 0.2 & - & \\
\hline Age class $†$ & 2 & 0.031 & 1.22 & 0.2 & - & \\
\hline
\end{tabular}


bioRxiv preprint doi: https://doi.org/10.1101/2022.01.04.474987; this version posted January 5, 2022. The copyright holder for this preprint (which was not certified by peer review) is the author/funder, who has granted bioRxiv a license to display the preprint in perpetuity. It is made available under aCC-BY-NC-ND 4.0 International license.

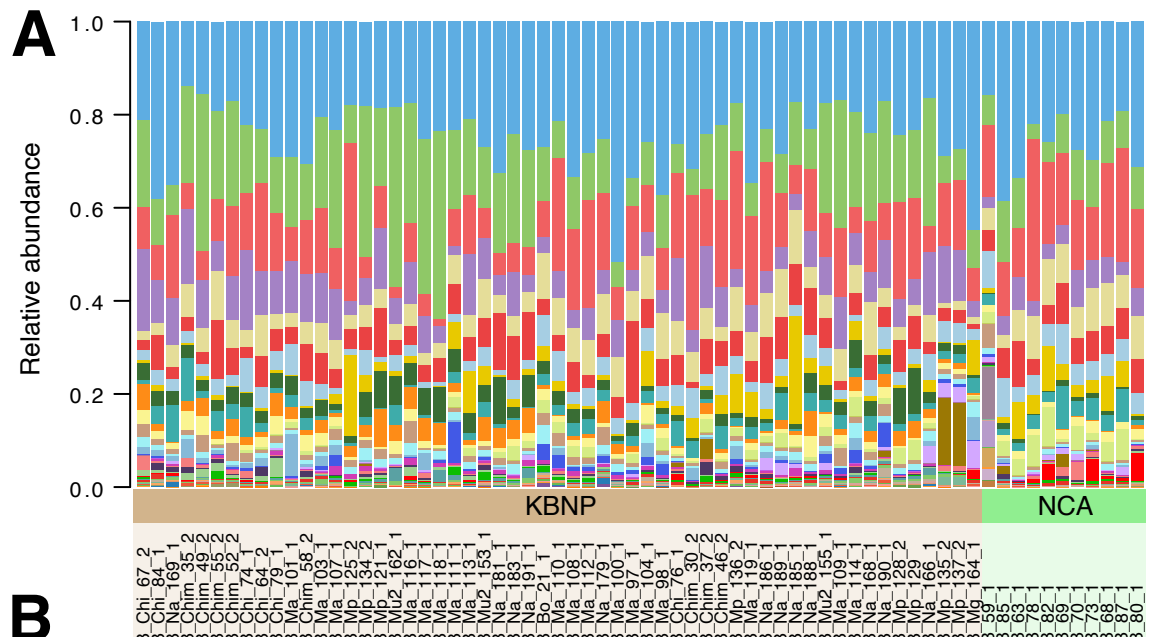

Top 25 gut microbial families

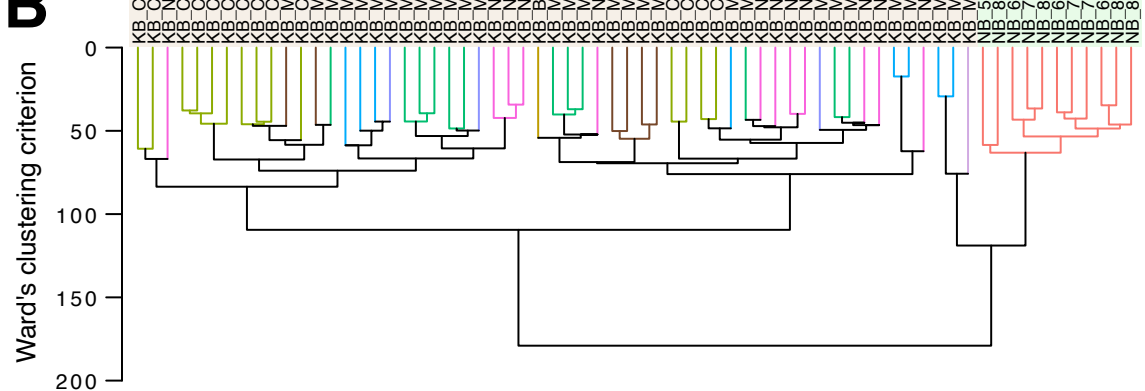

Lachnospiraceae

Rikenellaceae

Erysipelotrichaceae

Clostridiales Family XII

Christensenellaceae

Spirochaetaceae

Anaerolineacea

- Prevotellaceae

Muribaculaceae

Bacteroidales BS11 gut group

- Burkholderiaceae

Veillonellaceae

Bacteroidales p-251-05

- Methanomethylophilacea

Clostridiaceae 1

Puniceicoccaceae

Desulfovibrionaceae

Anaeroplasmataceae

Bacteroidales RF16 group

Succinivibrionacea

Paracaedibacteraceae
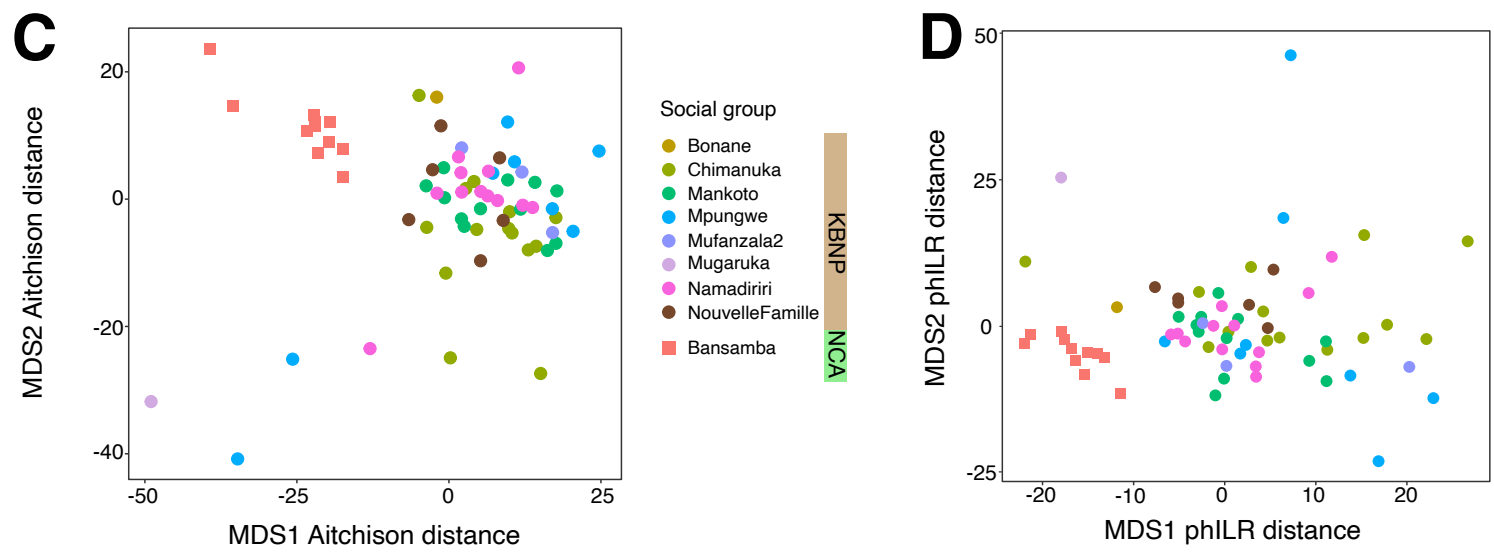

528 Figure 4. Gut microbiome composition at the family level (A) and differentiation based on compositional abundances of microbial ASVs (B-D). Gut microbiome clusters by population in CLR Aitchison distances dendrogram based on Ward's clustering criterion (Murtagh and Legendre 2014) (B), CLR Aitchison distances using NMDS (PERMANOVA R $\left.{ }^{2}=0.14, p=0.001\right)(C)$, and phILR Euclidean distances using NMDS $\left(\mathrm{R}^{2}=\right.$

$5320.15, \mathrm{p}=0.001)(\mathrm{D})$. 
Dietary and microbial profiles are correlated with each other

534

Although neither dietary richness nor evenness directly correlated with gut microbial richness

536 or evenness $(\rho<0.2, p=0.2$; Figure 5A), compositional differences in dietary and gut microbial

537 profiles showed significant co-inertia $(\mathrm{RV}=0.557, p<0.001$; Figure 5B $)$ and were correlated $(\rho=$

$538 \quad 0.32, p<0.001$; Figure 5C). Microbiome composition is known to change with diet in individuals and

539 also differs between populations with different dietary preferences (e.g., Muegge et al., 2011;

540 Youngblut et al., 2019). To investigate whether dietary differences across our study populations could

541 explain differences in gut microbial composition or, alternatively, if external factors influenced diet and

542 microbiome independently, we compared the effects of diet composition and geographical and social

543 variables on microbiome composition using an MRM model (Table 4). Population and social group

544 were the only predictor variables significantly correlated with microbiome composition, while neither

545 dietary composition nor geography had an effect after accounting for social group and population of

546 origin.

547

Table 4. MRM model comparing the effects of geography, diet, and sociodemographic factors on Grauer's gorilla gut microbiome composition $\dagger$

\begin{tabular}{|clcccc|}
\hline $\mathbf{N}$ & Explanatory variables & Spearman's $\boldsymbol{p}$ & $\boldsymbol{p}$ & $\mathbf{R}^{2}$ & F-statistic \\
& Geographic distance & 0.07 & 0.4 & & \\
& Altitudinal difference & -0.08 & 0.6 & & \\
& Diet composition $\dagger$ & -0.19 & 0.07 & 0.278 & 98.35 \\
& Population & $\mathbf{0 . 6 4}$ & $<\mathbf{0 . 0 0 1}$ & & \\
& Social group & $\mathbf{0 . 4 5}$ & $<\mathbf{0 . 0 0 1}$ & & \\
\hline
\end{tabular}

† Microbiome and diet composition in Aitchison distances. 
bioRxiv preprint doi: https://doi.org/10.1101/2022.01.04.474987; this version posted January $5,2022$. The copyright holder for this preprint (which was not certified by peer review) is the author/funder, who has granted bioRxiv a license to display the preprint in perpetuity. It is made available under aCC-BY-NC-ND 4.0 International license.
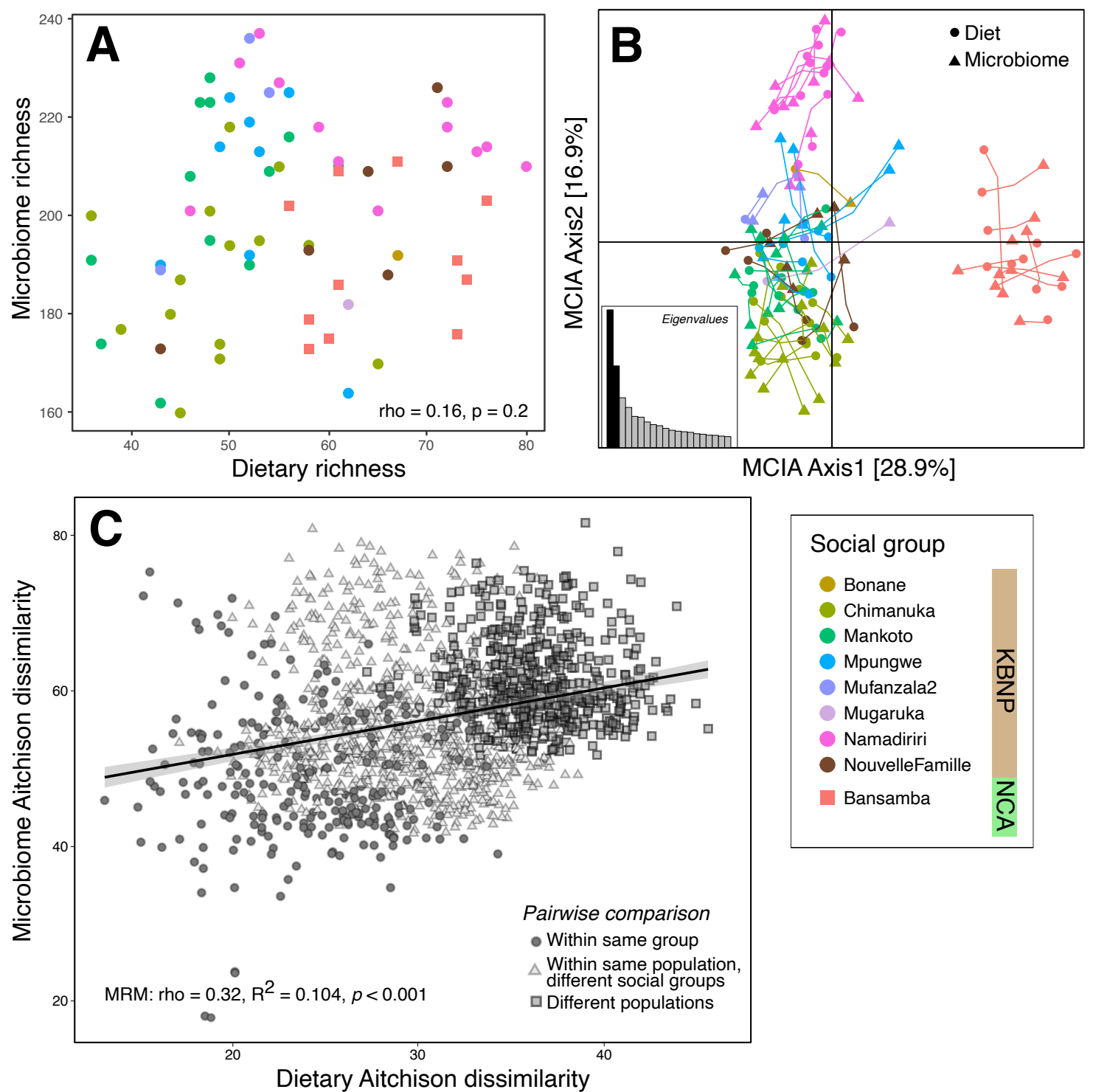

\section{Social group}

Bonane

Chimanuka

Mankoto

Mpungwe

Mufanzala2

Mugaruka

Namadiriri

NouvelleFamille

Bansamba

Figure 5. Relationship between diet and gut microbiome. (A) Microbiome and dietary richness, assessed as persample total sequence count, are not correlated $(\mathrm{p}=0.2)$. (B) High multiple co-inertia (MCIA) between microbiome and diet composition in CLR-transformed space with Aitchison distance (RV $=55.7 \%, \mathrm{MC} p<0.001$ based on 999 permutations). (C) Compositional differences (Aitchison distances) in diet and microbiome between samples (i.e., individual gorillas) are correlated in matrix regression. 
Discussion

559

We jointly characterized genetic and dietary profiles of three isolated populations of Grauer's

561 gorillas, one of which has never been studied before (Maiko NP). For two of these populations (Nkuba

562 Conservation Area and Kahuzi-Biega NP), we also characterized the gut microbiome. These

complementary datasets enabled direct evaluation of the role of social factors, host relatedness, and diet on gut microbial diversity and composition, thus allowing us to speculate on the importance of ecological differentiation for geographically isolated populations. Whether such a relationship exists and how it is determined is a central topic in ecology (Amato et al., 2019; Bolnick et al., 2014; Bueno de Mesquita et al., 2021; Gomez et al., 2016; Hicks et al., 2018; Muegge et al., 2011). We find that diet and microbiome profiles are correlated and differ between the study populations, likely as a result of habitat differences and social factors. Habitat- or behavioural-driven differentiation in dietary and gut microbial composition, concurrent with genetic differentiation, might be an indicator of processes relevant to local adaptation (Alberdi et al., 2016, 2020; Fietz et al., 2018; Henry et al., 2019; Kolodny et al., 2020; Moeller \& Sanders, 2020), which is of particular relevance to the design of effective conservation policy for these critically endangered apes.

In addition to traditional methods based on direct observations and feeding traces, molecular approaches provide further opportunities to detect rare dietary items, revealing a more complete picture of cryptic and rare species' nutritional ecology (Ait Baamrane et al., 2012; Bradley et al., 2007;

580 Goldberg et al., 2020; Hibert et al., 2013; Mallott, Garber, et al., 2018; Nawaz et al., 2019; Osman et al., 2020; Quéméré et al., 2013; Valentini et al., 2009). The approach is scalable to many individuals, is not biased towards habituated or approachable individuals, and provides data which can be compared across species (Kartzinel et al., 2019). Importantly, analysis of faecal samples minimizes disturbance and avoids influencing animal behaviour, aligning data collection with conservation goals (Jewell, 
587 Grauer's gorillas predominantly feed on vegetative plants, they occasionally consume insects and fungi

588 (van der Hoek, Pazo, et al., 2021; Yamagiwa et al., 1991). Yet by choosing a chloroplast gene, $\operatorname{trn} \mathrm{L}$,

589 we restricted dietary characterization in this study to plants only. There are also additional technical

590 limitations. By relying on a reference database for identification of plant taxa, metabarcoding

591 approaches are necessarily limited by the content of these databases (Taberlet et al., 2018). Similarly,

592 chosen thresholds for sequence identity and relative abundance could impact results. We used a

593 sequence identity threshold of $90 \%$, similar to other studies of tropical mammal diets via trnL, which

594 use thresholds between 90-95\% (Hibert et al., 2013; Quéméré et al., 2013; Srivathsan et al., 2016). We

595 also set a relative abundance threshold to greater than $0.05 \%$ in at least one sample, to filter out potential

596 sequencing and PCR errors, chimeric sequences, etc. It is possible, particularly due to the small size

597 and high variability of the $\operatorname{trn} \mathrm{L}$ locus, that our cut-offs removed some genuine dietary items.

598 Additionally, estimated abundances of the different plant taxa may not accurately reflect dietary

599 abundances (Deagle et al., 2019). DNA copy number can be biased by plant tissue type (i.e., fruit, pith,

600 leaves, the latter of which contain more chloroplasts; Egea et al., 2010), relative digestibility (i.e.,

601 amount of fibre), and PCR amplification success (reviewed by Deagle et al., 2019). Some of these issues

602 also arise with other approaches. For example, accuracy of macroscopic faecal analysis depends on the

603 types of tissues consumed and the extent of digestion (King \& Schoenecker, 2019), while observational

604 studies can overestimate the dietary importance of foods with longer handling times (Yamagiwa et al.,

605 2013).

606 Due to these limitations, it is important to establish how well the molecular results correspond

607 to traditional dietary analyses. The most abundant plant families detected in our study - Urticaceae,

608 Apocynaceae, Moraceae, Myristicaceae, and Primulaceae - were reported to be commonly consumed

609 by Grauer's gorillas in KBNP, based on feeding observations and faeces dissections (Yamagiwa et al.,

610 2005), and in NCA, based on feeding traces (van der Hoek, Pazo, et al., 2021). Vice versa, we detected

611 all top plant families reported in these observation-based studies, suggesting good correspondence

612 between our metabarcoding results and the literature on gorilla diet (van der Hoek, Pazo, et al., 2021;

613 Yamagiwa et al., 2005). 

consume either vegetative parts (e.g., Basellaceae, Oleaceae, Poaceae in KBNP and Myristicaceae,

616 Marantaceae, Arecaceae in NCA) or fruits (e.g., Moraceae, Euphorbiaceae, Sapindaceae, Piperaceae,

617 Primulaceae in KBNP and Vitaceae, Moraceae, Apocynaceae in NCA). This suggests that the $\operatorname{trn} \mathrm{L}$ 618 approach can capture both vegetation and fruits in the diet. In concordance with previous investigations 619 of the diet of gorillas in KBNP (Yamagiwa et al., 2005), Urera sp. was the most common taxon in our study (average abundance 21\%). It seems likely that this taxon corresponds to Urera hypselodendron, which gorillas in KBNP ate on 95\% of days (Yamagiwa et al., 2005). However, Urera bark is very fibrous, and an alternative explanation is that it preserves well in faeces and is thus easily detected. species Grauer's gorillas were reported to eat in one day in KBNP (17; Yamagiwa et al. 2005). It is possible that gorillas have more complex diets than focal follows, direct observations (usually limited from 24 to 60 hours in zoos (Remis, 2000), and therefore varied feeding or movement through varied habitats over several days could partially explain this discrepancy. Overall, the number of molecularly identified plant taxa (120) is similar to previous studies, which reported 116 food plants in KBNP

630 (Yamagiwa et al., 2005) and over 100 in NCA (van der Hoek et al. 2021).

Divergent dietary ecology between isolated populations

We found that the dietary profiles of gorillas differed significantly by population and by social group, with a unique suite of plants characterizing each population. Moreover, gorillas in NCA and MNP tended to have more species-rich diets compared to KBNP. These two sites are $1500 \mathrm{~m}$ lower in elevation than KBNP. Even within the KBNP population, we observed the highest dietary diversity in the social group sampled at the lowest elevation (Namadiriri, $100 \mathrm{~m}$ below other social groups).

639 Globally, plant diversity tends to decrease with elevation (Rahbek, 1995), and this trend occurs within 640 KBNP too (Imani et al., 2016). Such an altitudinal diversity gradient is relevant for mountain gorillas, 641 who consume fewer species and spend more time feeding on herbaceous vegetation at higher elevation 
642 (Ganas et al., 2004). Taken together, our data thus support the theory that feeding in eastern gorillas is

643 at least partially determined by plant availability, with larger dietary repertoire at lower elevations.

644 Another plausible interpretation is that gorillas in low altitude NCA and MNP have greater daily ranges.

645 This could be driven by the search for fruit, suggested in NCA (van der Hoek, Binyinyi, et al., 2021).

646 Or, gorillas may travel further to acquire sufficient nutrition due to potential degradation of habitat in

647 the low-elevation sites, relative to protected KBNP (Maldonado et al., 2012). Such increased mobility could place individuals at even greater risk to poaching.

We identified 21 taxa that have not previously been reported in the Grauer's gorilla diet. Some 650 of these occur in KBNP (e.g., various Apocynaceae tribes, non-native Cactaceae, and Laurales like 651 Ocotea usambarensis; Spira et al., 2018; Yumoto et al., 1994), and some are eaten by mountain gorillas 652 (e.g., Solanum, Solanoideae; Rothman et al., 2014; Watts, 1984) or western lowland gorillas (e.g., Beilschmiedia, Laruales; Remis et al., 2001). Others, such as Gnetum sp. and Humiriaceae sp., have not been recorded in KBNP, but are western lowland gorilla foods (Rogers et al., 2004; Takenoshita \& Yamagiwa, 2008). These taxa were significantly more common in the understudied NCA and MNP sites, suggesting that gorillas incorporate locally available plants into their diet. Another possibility is that these taxa are environmental "contaminants", such as building material of night nests from which samples were collected.

Other studies have documented the importance of season in gorilla diet, as gorillas seasonally increase fruit consumption (van der Hoek, Pazo, et al., 2021; Yamagiwa \& Basabose, 2006). Our ability to evaluate the effect of season was limited by sampling. For example, gorillas in MNP had a compositionally distinct diet, and these samples were collected later in the year. Still, the two populations sampled at similar timepoints, NCA and most of KBNP, also diverged in diet and microbiome. It is thus possible that the divergences that we observed are partially due to seasonal factors, but further sampling is necessary to elucidate the effect of season.

666 
671 Chloroflexi, Actinobacteria, Proteobacteria; Campbell et al., 2020; Gomez et al., 2016; Hicks et al.,

672 2018; Nishida \& Ochman, 2019). Like other gorilla subspecies, the abundance of Chloroflexi and

673 Spirochaetes in the wild Grauer's gorilla gut microbiome is strikingly high compared to Old World monkeys and humans (Gomez et al. 2016, Hicks et al. 2018, Campbell et al. 2020). However, there were differences in the relative abundance of each of the major phyla compared to wild western lowland

676 gorillas, with the Grauer's gorilla gut microbiomes showing proportionally fewer Actinobacteria and

677 Chloroflexi, but more Firmicutes, Bacteroidetes, and Spirochaetes (Campbell et al., 2020; Fontsere et al., 2021; Hicks et al., 2018). Specifically, the relative abundance of Firmicutes in Grauer's gorilla microbiomes was higher (64.7\% average) compared to western lowland (42-53\%; Campbell et al., 2020; Fontsere et al., 2021; Hicks et al., 2018) and mountain gorillas (34\%, Gomez et al. 2016). The abundance of Bacteroidetes (21.0\%) was intermediate between western lowland (10-19\%; Campbell et al., 2020; Fontsere et al., 2021; Hicks et al., 2018) and mountain gorillas (30\%, Gomez et al. 2016). Higher ratios of Firmicutes-to-Bacteroidetes are thought to indicate greater energy extraction potential (Mariat et al. 2009) and decline in captivity (Clayton et al. 2018). Thus, the relatively high F:B ratio in Grauer's gorillas here might facilitate efficient metabolism of their fibrous food resources $[\log (\mathrm{F}: \mathrm{B})=$ 1.12 in this study compared to $\log (\mathrm{F}: \mathrm{B})<1$ in wild western lowland gorillas, Hicks et al. 2018]. Further, we detected higher gut microbiome alpha diversity in Grauer's gorillas (13 phyla/sample) than reported for western lowland gorillas (9), chimpanzees (9), and humans ( $<5$, Hicks et al., 2018), suggesting either higher diversity of Grauer's gorilla microbiomes or better characterisation of rare phyla in our study (e.g., Patescibacteria, Epsilonbacteraeota).

We identified eleven microbial taxa present in every individual in this dataset. As these are shared by individuals living up to $175 \mathrm{~km}$ apart, they may be functionally important. Many of the these are carbohydrate- and fibre-degraders related to common members of western lowland gorilla microbiomes that were much more common in wild vs. captive individuals, e.g. Flexilinea (Chloroflexi;

695 Anaerolineaceae), Prevotella 7 (Bacteroidetes; Prevotellaceae), and Ruminococcus (Firmicutes; 696 Ruminococcaceae) (Campbell et al., 2020; Hicks et al., 2018; Narat et al., 2020). However, some of 
these core taxa were not particularly common in previous studies of gorilla microbiomes, e.g.,

698 Senegalimassilia (Actinobacteria; Eggerthellaceae) and Sutterella (Gammaproteobacteria;

699 Burkholderiaceae), though they are common in the gut of baboons (Grieneisen et al., 2021), geladas

700 (Baniel et al., 2021), white-faced capuchins, (Mallott, Amato, et al., 2018), and woolly monkeys

701 (Quiroga-González et al., 2021). The gut microbiome of Grauer's gorillas appeared to be relatively

stable through time, as evidenced by greater similarity amongst samples from the same individuals

703

collected almost one year apart compared to other individuals from the same social group, a finding generally in agreement with studies on the human gut microbiome (Björk et al., 2019; Faith et al., 2013).

Gut microbiome differs between populations and social groups

707

The Grauer's gorilla gut microbiome differed between populations separated by large geographic and genetic distances and also across social groups. As we found no effect of genetic relatedness, it is likely that contact and social association with groupmates explains why individuals from the same social group show greater similarity in their gut microbiome than to individuals from other social groups within the same population. Time spent in close proximity offers opportunities for transfer of gut microbiota, such as through grooming and coprophagy (Graczyk \& Cranfield, 2003). An effect of social association on the gut microbiome has previously been identified for a range of primates, including chimpanzees (Degnan et al., 2012; Moeller et al., 2016), baboons (Tung et al., 2015), colobus monkeys (Wikberg et al., 2020), black howler monkeys (Amato et al., 2017), sifakas (Perofsky et al., 2017, 2021), and humans (Dill-McFarland et al., 2019), as well as other group-living animals, e.g. bighorn sheep (Couch et al., 2020). However, this does not preclude an effect of heritability. Longitudinal studies in Amboseli baboons have shown that there is a high heritability of the primate gut microbiome, which cannot easily be detected in shorter-term studies (Grieneisen et al., 2021). groups that drive the observed patterns. While diet was less important than population and social group identity in explaining variation in the gut microbiome, it is possible that dietary similarity among members of the same group drives convergence in the microbiome over longer time periods. This would 
imply limited between-group homogenization in diet, which could occur if groups have limited range overlap or restrict their foraging to particular areas. Since plant diversity in KBNP varies with altitude

727 (Imani et al., 2016), this is possible, particularly if gorilla groups forage only within their preferred altitudinal range, similar to the proposed patterns for female dispersal in the Bwindi mountain gorillas (Guschanski et al., 2008).

The gorilla gut microbiome is intertwined with diet determining microbiome diversity and composition (Clayton et al., 2018). Studies of wild primate populations frequently use proxies for diet, such as seasonal changes or environmental variables (e.g. forest type, habitat degradation) (Amato et al. 2019; Baniel et al. 2021; Bueno de Mesquita et al. 2021; and gut microbiome study). We add to this work by simultaneously characterizing diet and gut microbiome in two populations of wild Grauer's gorillas. In accordance with expectations from experimental work, we indeed detect high co-inertia and correlation between diet and microbiome composition. predictors of microbiome composition. This could indicate that microbial changes reflect long-term dietary patterns more consistent with social and ranging patterns than with diet at the precise time of sampling. Other local variables, such as abiotic and biotic environmental factors and the social environment may have additional effects on the gut microbiome. If diet and microbiome are linked, a more varied diet might be expected to select for a more complex gut microbiome. However, in contrast to findings in healthy humans (Heiman \& Greenway, 2016), the low-altitude population that had higher dietary richness did not show higher gut microbial richness than the high-altitude population. In fact, the population with greater dietary evenness, NCA, had significantly lower gut microbial evenness. To understand if this relative lack of microbial diversity indicates nutritional redundancy in the diet of NCA gorillas requires further investigation into the nutritional diversity of the plant species consumed. 

derive from differences in specific taxa within universally common bacterial families, especially digestive function across populations of the same species (Amato et al., 2019). There were, however, several family-level differences. For instance, Treponema (Spirochaetaceae) were more abundant in NCA, whereas Prevotella (Prevotellaceae) were more abundant in KBNP. Hicks et al. (2018) found Treponema in western gorillas associated with high-fibre fallback foods, like Marantaceae, Moraceae, and Zingeraceae. The genus Prevotella, meanwhile, was enriched during periods of high fruit abundance (e.g., Annonaceae, and Urticaceae) (Hicks et al., 2018). Prevotella is common in carbohydrate-rich diets in other studies as well, and is sometimes associated with captivity (Campbell et al., 2020; Clayton et al., 2016; Hicks et al., 2018; Precup \& Vodnar, 2019). Consistent with these reports, we found greater abundance of Marantaceae, Moraceae, Commelinaceae, and Zingeraceae in diets of NCA Grauer's gorillas, which had more Treponema, and greater abundance of Urticaceae, Primulaceae, Sapindaceae, and Piperaceae in KBNP, where Prevotella was more abundant. While speculation about functional correlations is possible, alternate approaches, such as shotgun metagenomics coupled with deeper characterization of global bacterial diversity and metabolic function would further enhance our understanding of the relationship between diet and microbial communities.

\section{Conclusions}

We provide evidence that fragmented and genetically differentiated populations of critically endangered Grauer's gorillas differ in dietary and gut microbiome composition, suggesting that they might be locally adapted. We emphasize the utility of faecal sampling for minimally-invasive population monitoring of different aspects of endangered species biology, from genetics to ecology to foraging behaviour. Despite its limitations, a molecular approach can reveal otherwise clandestine insights into the ecology of elusive animals and is particularly powerful when combined with traditional field observational methods. Our results stress the importance of protecting geographically-isolated wildlife populations, as safeguarding ecological and genetic biodiversity is the objective of species conservation. 


\section{Acknowledgements}

782 We thank L'Institut Congolais pour la Conservation de la Nature (ICCN) and local landowners and 783 community members, for permitting us to work in the Kahuzi-Biega National Park and the Nkuba

784 Conservation Area. We are indebted to numerous rangers and field assistants in Kahuzi-Biega National

785 Park as well as field assistants, gorilla trackers, and local community members in Nkuba Conservation Area who, through their effort and commitment, support this project and ensure the survival of the Grauer's gorillas. This research was supported by the Royal Physiographic Society of Lund Jan Löfqvist and Nilsson-Ehle Endowments to KG and the Erasmus Mundus Master Programme in Evolutionary Biology Consortium Scholarship to AM. The Dian Fossey Gorilla Fund's work in DRC was supported by individual donations and grants from the Great Ape Conservation Fund of the US Fish and Wildlife Service, the Arcus Foundation, the Daniel L. Thorne Foundation, and the Turner Foundation. Sequencing was performed by the SNP\&SEQ Technology Platform in Uppsala. The SNP\&SEQ Technology Platform is part of the National Genomics Infrastructure Sweden and Science of Life Laboratory. The SNP\&SEQ Platform is also supported by the Swedish Research Council and the Knut and Alice Wallenberg Foundation. We also acknowledge the National Bioinformatics Infrastructure for providing computational resources to this project.

\section{Author contribution}

AM, RM and KG planned the study design. AM generated dietary data and performed all analyses. RM generated gut microbial data. PN, YL, MAG, and JS generated gorilla genotyping data. KN and LP

801 provided reagents and expertise for dietary analyses. NI, AP, UN, EB, RNP, DC, and KG collected 802 faecal samples and provided support in the field. DC, LP and KG provided project supervision. KG 803 supervised the experiments and data analyses. AM and KG wrote the manuscript, with contribution 804 from all authors. All authors reviewed and approved of the final manuscript.

\section{Data availability}

807 Sequences for the gut microbiome and diet generated in this project have been uploaded to the European 808 Nucleotide Archive (ENA) under Accession no.: PRJEB49814. 


\section{References}

Agranyoni, O., Meninger-Mordechay, S., Uzan, A., Ziv, O., Salmon-Divon, M., Rodin, D., Raz, O., Koman, I., Koren, O., Pinhasov, A., \& Navon-Venezia, S. (2021). Gut microbiota determines the social behavior of mice and induces metabolic and inflammatory changes in their adipose tissue. Npj Biofilms and Microbiomes, 7(1), 1-14. https://doi.org/10.1038/s41522-021-00193-9

Ait Baamrane, M. A., Shehzad, W., Ouhammou, A., Abbad, A., Naimi, M., Coissac, E., Taberlet, P., \& Znari, M. (2012). Assessment of the food habits of the Moroccan dorcas gazelle in M'Sabih Talaa, west central Morocco, using the trnL approach. PLoS ONE, 7(4). https://doi.org/10.1371/journal.pone.0035643

Aitchison, J., Barceló-Vidal, C., Martín-Fernández, J. A., \& Pawlowsky-Glahn, V. (2000). Logratio analysis and compositional distance. Mathematical Geology, 32(3), 271-275.

Alberdi, A., Aizpurua, O., Bohmann, K., Zepeda-Mendoza, M. L., \& Gilbert, M. T. P. (2016). Do vertebrate gut metagenomes confer rapid ecological adaptation? Trends in Ecology and Evolution, 31(9), 689-699. https://doi.org/10.1016/j.tree.2016.06.008

Alberdi, A., Razgour, O., Aizpurua, O., Novella-Fernandez, R., Aihartza, J., Budinski, I., Garin, I., Ibáñez, C., Izagirre, E., Rebelo, H., Russo, D., Vlaschenko, A., Zhelyazkova, V., Zrnčić, V., \& Gilbert, M. T. P. (2020). DNA metabarcoding and spatial modelling link diet diversification with distribution homogeneity in European bats. Nature Communications, 11(1), 1-8. https://doi.org/10.1038/s41467-020-14961-2

Amato, K. R., G. Sanders, J., Song, S. J., Nute, M., Metcalf, J. L., Thompson, L. R., Morton, J. T., Amir, A., J. McKenzie, V., Humphrey, G., Gogul, G., Gaffney, J., L. Baden, A., A.O. Britton, G., P. Cuozzo, F., Di Fiore, A., J. Dominy, N., L. Goldberg, T., Gomez, A., ... R. Leigh, S. (2019). Evolutionary trends in host physiology outweigh dietary niche in structuring primate gut microbiomes. ISME Journal, 13(3), 576587. https://doi.org/10.1038/s41396-018-0175-0

Amato, K. R., Van Belle, S., Di Fiore, A., Estrada, A., Stumpf, R., White, B., Nelson, K. E., Knight, R., \& Leigh, S. R. (2017). Patterns in gut microbiota similarity associated with degree of sociality among sex classes of a neotropical primate. Microbial Ecology, 74(1), 250-258. https://doi.org/10.1007/s00248-0170938-6

Anderson, M. J., \& Walsh, D. C. I. (2013). PERMANOVA, ANOSIM, and the Mantel test in the face of heterogeneous dispersions: what null hypothesis are you testing? Ecological Monographs, 83(4), 557574.

Arandjelovic, M., Guschanski, K., Schubert, G., Harris, T. R., Thalmann, O., Siedel, H., \& Vigilant, L. (2009). Two-step multiplex polymerase chain reaction improves the speed and accuracy of genotyping using DNA from noninvasive and museum samples. Molecular Ecology Resources, 9(1), 28-36. https://doi.org/10.1111/j.1755-0998.2008.02387.x

Arbizu, P. M. (2020). pairwiseAdonis: pairwise multilevel comparison using adonis. https://github. com/pmartinezarbizu/pairwiseAdonis.

Baas, P., van der Valk, T., Vigilant, L., Ngobobo, U., Binyinyi, E., Nishuli, R., Caillaud, D., \& Guschanski, K. (2018). Population-level assessment of genetic diversity and habitat fragmentation in critically endangered Grauer's gorillas. American Journal of Physical Anthropology, 165(3), 565-575. https://doi.org/10.1002/ajpa.23393

Baniel, A., Amato, K. R., Beehner, J. C., Bergman, T. J., Mercer, A., Perlman, R. F., Petrullo, L., Reitsema, L., Sams, S., Lu, A., \& Snyder-Mackler, N. (2021). Seasonal shifts in the gut microbiome indicate plastic responses to diet in wild geladas. Microbiome, 9(1), 1-20. https://doi.org/10.1186/s40168-020-00977-9

Bates, D., Maechler, M., Bolker, B. M., \& Walker, S. (2015). Fitting linear mixed-effects models using lme4. Journal of Statistical Software, 67(1), 1-48.

Beja-Pereira, A., Oliveira, R., Alves, P. C., Schwartz, M. K., \& Luikart, G. (2009). Advancing ecological understandings through technological transformations in noninvasive genetics. Molecular Ecology Resources, 9(5), 1279-1301. https://doi.org/10.1111/j.1755-0998.2009.02699.x

Björk, J. R., Dasari, M., Grieneisen, L., \& Archie, E. A. (2019). Primate microbiomes over time: Longitudinal answers to standing questions in microbiome research. American Journal of Primatology, 81(10-11), 123. https://doi.org/10.1002/ajp.22970

Bolnick, D. I., Snowberg, L. K., Hirsch, P. E., Lauber, C. L., Knight, R., Caporaso, J. G., \& Svanbäck, R. (2014). Individuals' diet diversity influences gut microbial diversity in two freshwater fish (threespine stickleback and Eurasian perch). Ecology Letters, 17(8), 979-987. https://doi.org/10.1111/ele.12301

Boyer, F., Mercier, C., Bonin, A., Le Bras, Y., Taberlet, P., \& Coissac, E. (2016). obitools: A unix-inspired software package for DNA metabarcoding. Molecular Ecology Resources, 16(1), 176-182.

Bradley, B. J., Chambers, K. E., \& Vigilant, L. (2001). Accurate DNA-based sex identification of apes using non-invasive samples. Conservation Genetics, 2(2), 179-181. https://doi.org/10.1023/A:1011847528045

Bradley, B. J., Stiller, M., Doran-Sheehy, D. M., Harris, T., Chapman, C. A., Vigilant, L., \& Poinar, H. (2007). Plant DNA sequences from feces: Potential means for assessing diets of wild primates. American Journal of Primatology, 69(6), 699-705. https://doi.org/10.1002/ajp.20384 
Brealey, J. C., Leitão, H. G., Hofstede, T., Kalthoff, D. C., \& Guschanski, K. (2021). The oral microbiota of wild bears in Sweden reflects the history of antibiotic use by humans. Current Biology, 31(20), 46504658.e6. https://doi.org/10.1016/j.cub.2021.08.010

Brealey, J. C., Leitão, H. G., Van-Der-Valk, T., Xu, W., Bougiouri, K., Dalén, L., \& Guschanski, K. (2020). Dental calculus as a tool to study the evolution of the mammalian oral microbiome. Molecular Biology and Evolution, 37(10), 3003-3022. https://doi.org/10.1093/molbev/msaa135

Bueno de Mesquita, C. P., Nichols, L. M., Gebert, M. J., Vanderburgh, C., Bocksberger, G., Lester, J. D., Kalan, A. K., Dieguez, P., McCarthy, M. S., Agbor, A., Álvarez Varona, P., Ayimisin, A. E., Bessone, M., Chancellor, R., Cohen, H., Coupland, C., Deschner, T., Egbe, V. E., Goedmakers, A., ... Dunn, R. R. (2021). Structure of chimpanzee gut microbiomes across tropical Africa. MSystems, 6(3). https://doi.org/10.1128/msystems.01269-20

Cadotte, M. W., Carscadden, K., \& Mirotchnick, N. (2011). Beyond species: Functional diversity and the maintenance of ecological processes and services. Journal of Applied Ecology, 48(5), 1079-1087. https://doi.org/10.1111/j.1365-2664.2011.02048.x

Callahan, B. J., McMurdie, P. J., Rosen, M. J., Han, A. W., Johnson, A. J. A., \& Holmes, S. P. (2016). DADA2: High-resolution sample inference from Illumina amplicon data. Nature Methods, 13(7), 581-583. https://doi.org/10.1038/nmeth.3869

Campbell, T. P., Sun, X., Patel, V. H., Sanz, C., Morgan, D., \& Dantas, G. (2020). The microbiome and resistome of chimpanzees, gorillas, and humans across host lifestyle and geography. ISME Journal, 14(6), 1584-1599. https://doi.org/10.1038/s41396-020-0634-2

Ceballos, G., Ehrlich, P. R., \& Raven, P. H. (2020). Vertebrates on the brink as indicators of biological annihilation and the sixth mass extinction. Proceedings of the National Academy of Sciences of the United States of America, 117(24), 13596-13602. https://doi.org/10.1073/pnas.1922686117

Chao, A., Gotelli, N. J., Hsieh, T. C., Sander, E. L., Ma, K. H., Colwell, R. K., \& Ellison, A. M. (2014). Rarefaction and extrapolation with Hill numbers: a framework for sampling and estimation in species diversity studies. Ecological Monographs, 84(1), 45-67.

Chatterji, S., \& Pachter, L. (2006). Reference based annotation with GeneMapper. Genome Biology, 7(4), 1-10. Clayton, J. B., Al-Ghalith, G. A., Long, H. T., Tuan, B. Van, Cabana, F., Huang, H., Vangay, P., Ward, T., Minh, V. Van, Tam, N. A., Dat, N. T., Travis, D. A., Murtaugh, M. P., Covert, H., Glander, K. E., Nadler, T., Toddes, B., Sha, J. C. M., Singer, R., ... Johnson, T. J. (2018). Associations between nutrition, gut microbiome, and health in a novel nonhuman primate model. Scientific Reports, 8(1), 1-16. https://doi.org/10.1038/s41598-018-29277-x

Clayton, J. B., Vangay, P., Huang, H., Ward, T., Hillmann, B. M., Al-Ghalith, G. A., Travis, D. A., Long, H. T., Van Tuan, B., Van Minh, V., Cabana, F., Nadler, T., Toddes, B., Murphy, T., Glander, K. E., Johnson, T. J., \& Knights, D. (2016). Captivity humanizes the primate microbiome. Proceedings of the National Academy of Sciences of the United States of America, 113(37), 10376-10381. https://doi.org/10.1073/pnas.1521835113

Colston, T. J., \& Jackson, C. R. (2016). Microbiome evolution along divergent branches of the vertebrate tree of life: what is known and unknown. Molecular Ecology, 25(16), 3776-3800. https://doi.org/10.1111/mec.13730

Correa, F., Torti, V., Spiezio, C., Checcucci, A., Modesto, M., Borruso, L., Cavani, L., Mimmo, T., Cesco, S., Luise, D., Randrianarison, R. M., Gamba, M., Rarojoson, N. J., Sanguinetti, M., Di Vito, M., Bugli, F., Mattarelli, P., Trevisi, P., Giacoma, C., \& Sandri, C. (2021). Disentangling the possible drivers of Indri indri microbiome: A threatened lemur species of Madagascar. Frontiers in Microbiology, 12(August), 112. https://doi.org/10.3389/fmicb.2021.668274

Couch, C. E., Arnold, H. K., Crowhurst, R. S., Jolles, A. E., Sharpton, T. J., Witczak, M. F., Epps, C. W., \& Beechler, B. R. (2020). Bighorn sheep gut microbiomes associate with genetic and spatial structure across a metapopulation. Scientific Reports, 10(1), 1-10. https://doi.org/10.1038/s41598-020-63401-0

Davidson, G. L., Raulo, A., \& Knowles, S. C. L. (2020). Identifying microbiome-mediated behaviour in wild vertebrates. Trends in Ecology and Evolution, 35(11), 972-980. https://doi.org/10.1016/j.tree.2020.06.014

Deagle, B. E., Thomas, A. C., McInnes, J. C., Clarke, L. J., Vesterinen, E. J., Clare, E. L., Kartzinel, T. R., \& Eveson, J. P. (2019). Counting with DNA in metabarcoding studies: How should we convert sequence reads to dietary data? Molecular Ecology, 28(2), 391-406. https://doi.org/10.1111/mec.14734

Degnan, P. H., Pusey, A. E., Lonsdorf, E. V., Goodall, J., Wroblewski, E. E., Wilson, M. L., Rudicell, R. S., Hahn, B. H., \& Ochman, H. (2012). Factors associated with the diversification of the gut microbial communities within chimpanzees from Gombe National Park. Proceedings of the National Academy of Sciences of the United States of America, 109(32), 13034-13039. https://doi.org/10.1073/pnas.1110994109

Delgado-Baquerizo, M., Oliverio, A. M., Brewer, T. E., Benavent-González, A., Eldridge, D. J., Bardgett, R. D., Maestre, F. T., Singh, B. K., \& Fierer, N. (2018). A global atlas of the dominant bacteria found in soil. Science, 359(6373), 320-325. https://doi.org/10.1126/science.aap9516 
DeSantis, T. Z., Hugenholtz, P., Larsen, N., Rojas, M., Brodie, E. L., Keller, K., Huber, T., Dalevi, D., Hu, P., \& Andersen, G. L. (2006). Greengenes, a chimera-checked 16S rRNA gene database and workbench compatible with ARB. Applied and Environmental Microbiology, 72(7), 5069-5072.

DeWoody, J. A., Harder, A. M., Mathur, S., \& Willoughby, J. R. (2021). The long-standing significance of genetic diversity in conservation. Molecular Ecology, 30(17), 4147-4154. https://doi.org/10.1111/mec.16051

Dill-McFarland, K. A., Tang, Z. Z., Kemis, J. H., Kerby, R. L., Chen, G., Palloni, A., Sorenson, T., Rey, F. E., \& Herd, P. (2019). Close social relationships correlate with human gut microbiota composition. Scientific Reports, 9(1), 1-10. https://doi.org/10.1038/s41598-018-37298-9

Edgar, R. C. (2018). Updating the 97\% identity threshold for 16 S ribosomal RNA OTUs. Bioinformatics, 34(14), 2371-2375. https://doi.org/10.1093/bioinformatics/bty113

Egea, I., Barsan, C., Bian, W., Purgatto, E., Latché, A., Chervin, C., Bouzayen, M., \& Pech, J. C. (2010). Chromoplast differentiation: Current status and perspectives. Plant and Cell Physiology, 51(10), 16011611. https://doi.org/10.1093/pcp/pcq136

Eisenhofer, R., Minich, J. J., Marotz, C., Cooper, A., Knight, R., \& Weyrich, L. S. (2019). Contamination in low microbial biomass microbiome studies: issues and recommendations. Trends in Microbiology, 27(2), $105-117$.

Escoufier, Y. (1973). Le traitement des variables vectorielles. Biometrics, 29(4), 751. https://doi.org/10.2307/2529140

Evanno, G., Regnaut, S., \& Goudet, J. (2005). Detecting the number of clusters of individuals using the software STRUCTURE: a simulation study. Molecular Ecology, 14(8), 2611-2620.

Faith, J. J., Guruge, J. L., Charbonneau, M., Subramanian, S., Seedorf, H., Goodman, A. L., Clemente, J. C., Knight, R., Heath, A. C., Leibel, R. L., Rosenbaum, M., \& Gordon, J. I. (2013). The long-term stability of the human gut microbiota. Science, 341(6141). https://doi.org/10.1126/science.1237439

Falush, D., Stephens, M., \& Pritchard, J. K. (2003). Inference of population structure using multilocus genotype data: linked loci and correlated allele frequencies. Genetics, 164(4), 1567-1587.

Ficetola, G. F., Coissac, E., Zundel, S., Riaz, T., Shehzad, W., Bessière, J., Taberlet, P., \& Pompanon, F. (2010). An in silico approach for the evaluation of DNA barcodes. BMC Genomics, 11(1), 1-10.

Fietz, K., Rye Hintze, C. O., Skovrind, M., Kjærgaard Nielsen, T., Limborg, M. T., Krag, M. A., Palsbøll, P. J., Hestbjerg Hansen, L., Rask Møller, P., \& Gilbert, M. T. P. (2018). Mind the gut: Genomic insights to population divergence and gut microbial composition of two marine keystone species. Microbiome, 6(1), 1-16. https://doi.org/10.1186/s40168-018-0467-7

Fontsere, C., Frandsen, P., Hernandez-Rodriguez, J., Niemann, J., Scharff-Olsen, C. H., Vallet, D., Le Gouar, P., Ménard, N., Navarro, A., Siegismund, H. R., Hvilsom, C., Gilbert, M. T. P., Kuhlwilm, M., Hughes, D., \& Marques-Bonet, T. (2021). The genetic impact of an Ebola outbreak on a wild gorilla population. BMC Genomics, 22(1). https://doi.org/10.1186/s12864-021-08025-y

Foster, Z. S. L., Sharpton, T. J., \& Grünwald, N. J. (2017). Metacoder: An R package for visualization and manipulation of community taxonomic diversity data. PLoS Computational Biology, 13(2), e1005404.

Francis, R. M. (2017). pophelper: an R package and web app to analyse and visualize population structure. Molecular Ecology Resources, 17(1), 27-32.

Ganas, J., Robbins, M. M., Nkurunungi, J. B., Kaplin, B. A., \& McNeilage, A. (2004). Dietary variability of mountain gorillas in Bwindi Impenetrable National Park, Uganda. International Journal of Primatology, 25(5), 1043-1072. https://doi.org/10.1023/B:IJOP.0000043351.20129.44

Gloor, G. B., Macklaim, J. M., Pawlowsky-Glahn, V., \& Egozcue, J. J. (2017). Microbiome datasets are compositional: and this is not optional. Frontiers in Microbiology, 8, 2224.

Goldberg, A. R., Conway, C. J., Tank, D. C., Andrews, K. R., Gour, D. S., \& Waits, L. P. (2020). Diet of a rare herbivore based on DNA metabarcoding of feces: Selection, seasonality, and survival. Ecology and Evolution, 10(14), 7627-7643. https://doi.org/10.1002/ece3.6488

Gomez, A., Petrzelkova, K., Yeoman, C. J., Vlckova, K., Mrázek, J., Koppova, I., Carbonero, F., Ulanov, A., Modry, D., Todd, A., Torralba, M., Nelson, K. E., Gaskins, H. R., Wilson, B., Stumpf, R. M., White, B. A., \& Leigh, S. R. (2015). Gut microbiome composition and metabolomic profiles of wild western lowland gorillas (Gorilla gorilla gorilla) reflect host ecology. Molecular Ecology, 24(10), 2551-2565. https://doi.org/10.1111/mec.13181

Gomez, A., Rothman, J. M., Petrzelkova, K., Yeoman, C. J., Vlckova, K., Umaña, J. D., Carr, M., Modry, D., Todd, A., Torralba, M., Nelson, K. E., Stumpf, R. M., Wilson, B. A., Blekhman, R., White, B. A., \& Leigh, S. R. (2016). Temporal variation selects for diet-microbe co-metabolic traits in the gut of Gorilla spp. ISME Journal, 10(2), 514-526. https://doi.org/10.1038/ismej.2015.146

Goslee, S. C., \& Urban, D. L. (2007). The ecodist package for dissimilarity-based analysis of ecological data. Journal of Statistical Software, 22(1), 1-19.

Graczyk, T. K., \& Cranfield, M. R. (2003). Coprophagy and intestinal parasites: implications to humanhabituated mountain gorillas (Gorilla gorilla beringei) of the Virunga Mountains and Bwindi Impenetrable 
Forest. Primate Conservation, 9, 58-64.

Grieneisen, L., Dasari, M., Gould, T. J., Björk, J. R., Grenier, J. C., Yotova, V., Jansen, D., Gottel, N., Gordon, J. B., Learn, N. H., Gesquiere, L. R., Wango, T. L., Mututua, R. S., Warutere, J. K., Siodi, L., Gilbert, J. A., Barreiro, L. B., Alberts, S. C., Tung, J., ... Blekhman, R. (2021). Gut microbiome heritability is nearly universal but environmentally contingent. Science, 373(6551), 181-186. https://doi.org/10.1126/science.aba5483

Guschanski, K., Caillaud, D., Robbins, M. M., \& Vigilant, L. (2008). Females shape the genetic structure of a gorilla population. Current Biology, 18(22), 1809-1814. https://doi.org/10.1016/j.cub.2008.10.031

Haddad, N. M., Brudvig, L. A., Clobert, J., Davies, K. F., Gonzalez, A., Holt, R. D., Lovejoy, T. E., Sexton, J. O., Austin, M. P., Collins, C. D., Cook, W. M., Damschen, E. I., Ewers, R. M., Foster, B. L., Jenkins, C. N., King, A. J., Laurance, W. F., Levey, D. J., Margules, C. R., ... Townshend, J. R. (2015). Habitat fragmentation and its lasting impact on Earth's ecosystems. Science Advances, 1(2), 1-10. https://doi.org/10.1126/sciadv.1500052

Harcourt, A. H., \& Stewart, K. J. (2013). Gorilla Society: Conflict, Compromise, and Cooperation Between the Sexes. The University of Chicago Press. https://doi.org/10.7208/chicago/9780226316048.001.0001

Heiman, M. L., \& Greenway, F. L. (2016). A healthy gastrointestinal microbiome is dependent on dietary diversity. Molecular Metabolism, 5(5), 317-320. https://doi.org/10.1016/j.molmet.2016.02.005

Henry, L. P., Bruijning, M., Forsberg, S. K. G., \& Ayroles, J. F. (2019). Can the microbiome influence host evolutionary trajectories? BioRxiv, 700237. https://doi.org/10.1101/700237

Hibert, F., Taberlet, P., Chave, J., Scotti-Saintagne, C., Sabatier, D., \& Richard-Hansen, C. (2013). Unveiling the diet of elusive rainforest herbivores in next generation sequencing era? The tapir as a case study. PLoS ONE, 8(4). https://doi.org/10.1371/journal.pone.0060799

Hicks, A. L., Lee, K. J., Couto-Rodriguez, M., Patel, J., Sinha, R., Guo, C., Olson, S. H., Seimon, A., Seimon, T. A., Ondzie, A. U., Karesh, W. B., Reed, P., Cameron, K. N., Lipkin, W. I., \& Williams, B. L. (2018). Gut microbiomes of wild great apes fluctuate seasonally in response to diet. Nature Communications, 9(1). https://doi.org/10.1038/s41467-018-04204-w

Imani, G., Zapfack, L., Kalume, J., Riera, B., Cirimwami, L., \& Boyemba, F. (2016). Woody vegetation groups and diversity along the altitudinal gradient in mountain forest: case study of Kahuzi-Biega National Park and its surroundings, RD Congo. Journal of Biodiversity and Environmental Sciences, 8(6), 134-150. http://www.innspub.net

IUCN. (2016). Gorilla beringei ssp. graueri. The IUCN Red List of Threatened Species. https://doi.org/https://dx.doi.org/10.2305/IUCN.UK.2016-2.RLTS.T39995A17989838.en

IUCN. (2021). The IUCN Red List of Threatened Species. https://www.iucn.org/.

Jakobsson, M., \& Rosenberg, N. A. (2007). CLUMPP: a cluster matching and permutation program for dealing with label switching and multimodality in analysis of population structure. Bioinformatics, 23(14), 18011806.

Jewell, Z. (2013). Effect of monitoring technique on quality of conservation science. Conservation Biology, 27(3), 501-508. https://doi.org/10.1111/cobi.12066

Jombart, T. (2008). adegenet: a R package for the multivariate analysis of genetic markers. Bioinformatics, 24(11), 1403-1405.

Kalinowski, S. T., Taper, M. L., \& Marshall, T. C. (2007). Revising how the computer program CERVUS accommodates genotyping error increases success in paternity assignment. Molecular Ecology, 16(5), 1099-1106. https://doi.org/10.1111/j.1365-294X.2007.03089.x

Kalinowski, S. T., Wagner, A. P., \& Taper, M. L. (2006). ML-RELATE: A computer program for maximum likelihood estimation of relatedness and relationship. Molecular Ecology Notes, 6(2), 576-579. https://doi.org/10.1111/j.1471-8286.2006.01256.x

Kambale, E. S. (2018). Diet selection strategies of Grauer's gorillas (Gorilla beringei graueri) in relation to nutritional benefits and exposure to heptotocix phytochemicals in Mount Tshiabirimu Forest, Virunga National Park, DRC. Makerere University.

Kamil, A. C., Krebs, J. R., \& Pulliam, H. R. (2012). Foraging behavior. Springer Science \& Business Media.

Kamvar, Z. N., Tabima, J. F., \& Grünwald, N. J. (2014). Poppr: an R package for genetic analysis of populations with clonal, partially clonal, and/or sexual reproduction. PeerJ, 2, e281.

Kandlikar, G. S., Gold, Z. J., Cowen, M. C., Meyer, R. S., Freise, A. C., Kraft, N. J. B., Moberg-Parker, J., Sprague, J., Kushner, D. J., \& Curd, E. E. (2018). ranacapa: An R package and Shiny web app to explore environmental DNA data with exploratory statistics and interactive visualizations. F1000Research, 7.

Kartzinel, T. R., Hsing, J. C., Musili, P. M., Brown, B. R. P., \& Pringle, R. M. (2019). Covariation of diet and gut microbiome in African megafauna. Proceedings of the National Academy of Sciences of the United States of America, 116(47), 23588-23593. https://doi.org/10.1073/pnas.1905666116

King, S. R. B., \& Schoenecker, K. A. (2019). Comparison of methods to examine diet of feral horses from noninvasively collected fecal samples. Rangeland Ecology and Management, 72(4), 661-666. https://doi.org/10.1016/j.rama.2019.02.005 
Kircher, M., Sawyer, S., \& Meyer, M. (2012). Double indexing overcomes inaccuracies in multiplex sequencing on the Illumina platform. Nucleic Acids Research, 40(1), e3-e3.

Kolodny, O., Callahan, B. J., \& Douglas, A. E. (2020). The role of the microbiome in host evolution. Philosophical Transactions of the Royal Society B: Biological Sciences, 375(1808), 20190588. https://doi.org/10.1098/rstb.2019.0588

Kopelman, N. M., Mayzel, J., Jakobsson, M., Rosenberg, N. A., \& Mayrose, I. (2015). CLUMPAK: a program for identifying clustering modes and packaging population structure inferences across K. Molecular Ecology Resources, 15(5), 1179-1191.

Lenth, R., Singmann, H., Love, J., Buerkner, P., \& Herve, M. (2021). Emmeans: Estimated marginal means, aka least-squares means. $R$ Package Version 1.7.0, 1(1), 3.

Ley, R. E., Lozupone, C. A., Hamady, M., Knight, R., \& Gordon, J. I. (2008). Worlds within worlds: Evolution of the vertebrate gut microbiota. Nature Reviews Microbiology, 6(10), 776-788. https://doi.org/10.1038/nrmicro1978

Lichstein, J. W. (2007). Multiple regression on distance matrices: a multivariate spatial analysis tool. Plant Ecology, 188(2), 117-131.

Maldonado, O., Aveling, C., Cox, D., Nixon, S., Merlo, D., Pintea, L., \& Williamson, E. A. (2012). Grauer's Gorillas and Chimpanzees in Eastern Democratic Republic of Congo (Kahuzi-Biega, Maiko, Tayna and Itombwe Landscape): Conservation Action Plan 2012-2022. IUCN.

Mallott, E. K., Amato, K. R., Garber, P. A., \& Malhi, R. S. (2018). Influence of fruit and invertebrate consumption on the gut microbiota of wild white-faced capuchins (Cebus capucinus). American Journal of Physical Anthropology, 165(3), 576-588. https://doi.org/10.1002/ajpa.23395

Mallott, E. K., Garber, P. A., \& Malhi, R. S. (2018). Trnl outperforms rbcl as a DNA metabarcoding marker when compared with the observed plant component of the diet of wild white-faced capuchins (Cebus capucinus, Primates). PLoS ONE, 13(6), 1-16. https://doi.org/10.1371/journal.pone.0199556

McMurdie, P. J., \& Holmes, S. (2013). phyloseq: an R package for reproducible interactive analysis and graphics of microbiome census data. PloS One, 8(4), e61217.

McNeilage, A., Robbins, M. M., Gray, M., Olupot, W., Babaasa, D., Bitariho, R., Kasangaki, A., Rainer, H., Asuma, S., Mugiri, G., \& Baker, J. (2006). Census of the mountain gorilla Gorilla beringei beringei population in Bwindi Impenetrable National Park, Uganda. ORYX, 40(4), 419-427. https://doi.org/10.1017/S0030605306001311

Meirmans, P. G. (2020). genodive version 3.0: Easy-to-use software for the analysis of genetic data of diploids and polyploids. Molecular Ecology Resources, 20(4), 1126-1131.

Meirmans, P. G., \& Hedrick, P. W. (2011). Assessing population structure: FST and related measures. Molecular Ecology Resources, 11(1), 5-18.

Meng, C., Kuster, B., Culhane, A. C., \& Gholami, A. M. (2014). A multivariate approach to the integration of multi-omics datasets. BMC Bioinformatics, 15(1), 1-13.

Meyer, M., \& Kircher, M. (2010). Illumina sequencing library preparation for highly multiplexed target capture and sequencing. Cold Spring Harbor Protocols, 5(6), 1-11. https://doi.org/10.1101/pdb.prot5448

Mirarab, S., Nguyen, N., \& Warnow, T. (2012). SEPP: SATé-enabled phylogenetic placement. Biocomputing, $247-258$.

Moeller, A. H., Foerster, S., Wilson, M. L., Pusey, A. E., Hahn, B. H., \& Ochman, H. (2016). Social behavior shapes the chimpanzee pan-microbiome. Science Advances, 2(1). https://doi.org/10.1126/sciadv.1500997

Moeller, A. H., \& Sanders, J. G. (2020). Roles of the gut microbiota in the adaptive evolution of mammalian species: Microbiotas alter mammalian adaptation. Philosophical Transactions of the Royal Society B: Biological Sciences, 375(1808), 1-10. https://doi.org/10.1098/rstb.2019.0597rstb20190597

Moran, N. A., Ochman, H., \& Hammer, T. J. (2019). Evolutionary and ecological consequences of gut microbial communities. Annual Review of Ecology, Evolution, and Systematics, 50, 451-475. https://doi.org/10.1146/annurev-ecolsys-110617-062453

Muegge, B. D., Kuczynski, J., Knights, D., Clemente, J. C., González, A., Fontana, L., Henrissat, B., Knight, R., \& Gordon, J. I. (2011). Diet drives convergence in gut microbiome functions across mammalian phylogeny and within humans. Science, 332(6032), 970-974. https://doi.org/10.1126/science.1198719

Murtagh, F., \& Legendre, P. (2014). Ward's hierarchical agglomerative clustering method: which algorithms implement Ward's criterion? Journal of Classification, 31(3), 274-295.

Narat, V., Amato, K. R., Ranger, N., Salmona, M., Mercier-Delarue, S., Rupp, S., Ambata, P., Njouom, R., Simon, F., Giles-Vernick, T., \& LeGoff, J. (2020). A multi-disciplinary comparison of great ape gut microbiota in a central African forest and European zoo. Scientific Reports, 10(1), 1-15. https://doi.org/10.1038/s41598-020-75847-3

Nawaz, M. A., Valentini, A., Khan, N. K., Miquel, C., Taberlet, P., \& Swenson, J. E. (2019). Diet of the brown bear in Himalaya: Combining classical and molecular genetic techniques. PLoS ONE, 14(12), 1-21. https://doi.org/10.1371/journal.pone.0225698

Nishida, A. H., \& Ochman, H. (2019). A great-ape view of the gut microbiome. Nature Reviews Genetics, 
20(4), 195-206. https://doi.org/10.1038/s41576-018-0085-z

Nsubuga, A. M., Robbins, M. M., Roeder, A. D., Morin, P. A., Boesch, C., \& Vigilant, L. (2004). Factors affecting the amount of genomic DNA extracted from ape faeces and the identification of an improved sample storage method. Molecular Ecology, 13(7), 2089-2094. https://doi.org/10.1111/j.1365294X.2004.02207.x

Oksanen, J., Blanchet, F. G., Kindt, R., Legendre, P., Minchin, P. R., O’Hara, R. B., Simpson, G. L., Solymos, P., Henry, M., \& Stevens, M. H. H. (2020). Vegan community ecology package: ordination methods, diversity analysis and other functions for community and vegetation ecologists. $R$ Package Version 2.5-7.

Osman, N. A., Abdul-Latiff, M. A. B., Mohd-Ridwan, A. R., Yaakop, S., Nor, S. M., \& Md-Zain, B. M. (2020). Diet composition of the wild stump-tailed macaque metabarcoding approach: A preliminary study. Animals, 10, 1-14.

Palarea-Albaladejo, J., \& Martín-Fernández, J. A. (2015). zCompositions-R package for multivariate imputation of left-censored data under a compositional approach. Chemometrics and Intelligent Laboratory Systems, 143, 85-96.

Perofsky, A. C., Ancel Meyers, L., Abondano, L. A., Di Fiore, A., \& Lewis, R. J. (2021). Social groups constrain the spatiotemporal dynamics of wild sifaka gut microbiomes. Molecular Ecology, September, 117. https://doi.org/10.1111/mec.16193

Perofsky, A. C., Lewis, R. J., Abondano, L. A., Difiore, A., \& Meyers, L. A. (2017). Hierarchical social networks shape gut microbial composition in wild verreaux's sifaka. Proceedings of the Royal Society B: Biological Sciences, 284(1868). https://doi.org/10.1098/rspb.2017.2274

Plumptre, A. J., Kirkby, A., Spira, C., Kivono, J., Mitamba, G., Ngoy, E., Nishuli, R., Strindberg, S., Maisels, F., Buckland, S., Ormsby, L., \& Kujirakwinja, D. (2021). Changes in Grauer's gorilla (Gorilla beringei graueri) and other primate populations in the Kahuzi-Biega National Park and Oku Community Reserve, the heart of Grauer's gorilla global range. American Journal of Primatology, 83(7). https://doi.org/10.1002/ajp.23288

Plumptre, A. J., Nixon, S., Kujirakwinja, D. K., Vieilledent, G., Critchlow, R., Williamson, E. A., Nishuli, R., Kirkby, A. E., \& Hall, J. S. (2016). Catastrophic decline of world's largest primate: $80 \%$ loss of grauer's gorilla (Gorilla beringei graueri) population justifies critically endangered status. PLoS ONE, 11(10). https://doi.org/10.1371/journal.pone.0162697

Porras-Hurtado, L., Ruiz, Y., Santos, C., Phillips, C., Carracedo, Á., \& Lareu, M. (2013). An overview of STRUCTURE: applications, parameter settings, and supporting software. Frontiers in Genetics, 4, 98.

Precup, G., \& Vodnar, D. C. (2019). Gut Prevotella as a possible biomarker of diet and its eubiotic versus dysbiotic roles: A comprehensive literature review. British Journal of Nutrition, 122(2), 131-140. https://doi.org/10.1017/S0007114519000680

Quast, C., Pruesse, E., Yilmaz, P., Gerken, J., Schweer, T., Yarza, P., Peplies, J., \& Glöckner, F. O. (2012). The SILVA ribosomal RNA gene database project: improved data processing and web-based tools. Nucleic Acids Research, 41(D1), D590-D596.

Quéméré, E., Hibert, F., Miquel, C., Lhuillier, E., Rasolondraibe, E., Champeau, J., Rabarivola, C., Nusbaumer, L., Chatelain, C., Gautier, L., Ranirison, P., Crouau-Roy, B., Taberlet, P., \& Chikhi, L. (2013). A DNA metabarcoding study of a primate dietary diversity and plasticity across its entire fragmented range. PLoS ONE, 8(3). https://doi.org/10.1371/journal.pone.0058971

Quiroga-González, C., Cardenas, L. A. C., Ramírez, M., Reyes, A., González, C., \& Stevenson, P. R. (2021). Monitoring the variation in the gut microbiota of captive woolly monkeys related to changes in diet during a reintroduction process. Scientific Reports, 11(1), 1-11. https://doi.org/10.1038/s41598-021-85990-0

R Core Team. (2021). R: A language and environment for statistical computing. $R$ Foundation for Statistical Computing. https://www.r-project.org/

Rahbek, C. (1995). The elevational gradient of species richness: a uniform pattern? Ecography, 18(2), $200-205$. https://doi.org/10.1111/j.1600-0587.1995.tb00341.x

Raymann, K., Moeller, A. H., Goodman, A. L., \& Ochman, H. (2017). Unexplored archaeal diversity in the great ape gut microbiome. MSphere, 2(1). https://doi.org/10.1128/msphere.00026-17

Raymond, M., \& Rousset, F. (1995). GENEPOP (Version 1.2): Population Genetics Software for Exact Tests and Ecumenicism. Journal of Heredity, 86(3), 248-249. https://doi.org/10.1093/oxfordjournals.jhered.a111573

Remis, M. J. (2000). Initial studies on the contributions of body size and gastrointestinal passage rates to dietary flexibility among gorillas. American Journal of Physical Anthropology, 112(2), 171-180. https://doi.org/10.1002/(SICI)1096-8644(2000)112:2<171::AID-AJPA4>3.0.CO;2-F

Remis, M. J., Dierenfeld, E. S., Mowry, C. B., \& Carroll, R. W. (2001). Nutritional aspects of western lowland gorilla (Gorilla gorilla gorilla) diet during seasons of fruit scarcity at Bai Hokou, Central African Republic. International Journal of Primatology, 22(5), 807-836. https://doi.org/10.1023/A:1012021617737

Ripple, W. J., Wolf, C., Newsome, T. M., Betts, M. G., Ceballos, G., Courchamp, F., Hayward, M. W., Van 
Valkenburgh, B., Wallach, A. D., \& Worm, B. (2019). Are we eating the world's megafauna to extinction? Conservation Letters, 12(3), 1-10. https://doi.org/10.1111/conl.12627

Robert, P., \& Escoufier, Y. (1976). A unifying tool for linear multivariate statistical methods: The RVcoefficient. Applied Statistics, 25(3), 257. https://doi.org/10.2307/2347233

Rogers, M. E., Abernethy, K., Bermejo, M., Cipolletta, C., Doran, D., Mcfarland, K., Nishihara, T., Remis, M., \& Tutin, C. E. G. (2004). Western gorilla diet: A synthesis from six sites. American Journal of Primatology, 64(2), 173-192. https://doi.org/10.1002/ajp.20071

Rohland, N., Harney, E., Mallick, S., Nordenfelt, S., \& Reich, D. (2015). Partial uracil - DNA - glycosylase treatment for screening of ancient DNA. Philosophical Transactions of the Royal Society B: Biological Sciences, 370(1660), 1-11. https://doi.org/10.1098/rstb.2013.0624

Rothman, J. M., Nkurunungi, J. B., Shannon, B. F., \& Bryer, M. A. H. (2014). High altitude diets: Implications for the feeding and nutritional ecology of mountain gorillas. In High Altitude Primates (pp. 247-264). Springer New York. https://doi.org/10.1007/978-1-4614-8175-1_14

Rousset, F. (2008). GENEPOP'007: A complete re-implementation of the GENEPOP software for Windows and Linux. Molecular Ecology Resources, 8(1), 103-106. https://doi.org/10.1111/j.14718286.2007.01931.x

Rudman, S. M., Greenblum, S., Hughes, R. C., Rajpurohit, S., Kiratli, O., Lowder, D. B., Lemmon, S. G., Petrov, D. A., Chaston, J. M., \& Schmidt, P. (2019). Microbiome composition shapes rapid genomic adaptation of Drosophila melanogaster. Proceedings of the National Academy of Sciences of the United States of America, 116(40), 20025-20032. https://doi.org/10.1073/pnas.1907787116

Schaller, G. E. (1963). The mountain gorilla: Ecology and behavior. University of Chicago Press.

Schwartz, M. K., Luikart, G., \& Waples, R. S. (2007). Genetic monitoring as a promising tool for conservation and management. Trends in Ecology and Evolution, 22(1), 25-33. https://doi.org/10.1016/j.tree.2006.08.009

Shehzad, W., Riaz, T., Nawaz, M. A., Miquel, C., Poillot, C., Shah, S. A., Pompanon, F., Coissac, E., \& Taberlet, P. (2012). Carnivore diet analysis based on next-generation sequencing: Application to the leopard cat (Prionailurus bengalensis) in Pakistan. Molecular Ecology, 21(8), 1951-1965.

Silverman, J. D., Washburne, A. D., Mukherjee, S., \& David, L. A. (2017). A phylogenetic transform enhances analysis of compositional microbiota data. Elife, 6, e21887.

Spira, C., Mitamba, G., Kirkby, A., Katembo, J., Kambale, C. K., Musikami, P., Dumbo, P., Byaombe, D.-D., Plumptre, A. J., \& Maisels, F. (2018). Inventaire de la biodiversite dans le Parc National de KahuziBiega, Republique Democratique du Congo.

Srivathsan, A., Ang, A., Vogler, A. P., \& Meier, R. (2016). Fecal metagenomics for the simultaneous assessment of diet, parasites, and population genetics of an understudied primate. Frontiers in Zoology, 13(1), 1-13. https://doi.org/10.1186/s12983-016-0150-4

Taberlet, P., Bonin, A., Zinger, L., \& Coissac, E. (2018). Environmental DNA: For biodiversity research and monitoring. Oxford University Press.

Taberlet, P., Coissac, E., Pompanon, F., Gielly, L., Miquel, C., Valentini, A., Vermat, T., Corthier, G., Brochmann, C., \& Willerslev, E. (2007). Power and limitations of the chloroplast trnL (UAA) intron for plant DNA barcoding. Nucleic Acids Research, 35(3), e14-e14. https://doi.org/10.1093/nar/gk1938

Takenoshita, Y., \& Yamagiwa, J. (2008). Estimating gorilla abundance by dung count in the northern part of Moukalaba-Doudou National Park, Gabon. African Study Monographs, Suppl. 39(April), 41-54. http://repository.kulib.kyoto-u.ac.jp/dspace/handle/2433/66239

Teixeira, J. C., \& Huber, C. D. (2021). The inflated significance of neutral genetic diversity in conservation genetics. Proceedings of the National Academy of Sciences of the United States of America, 118(10), 110. https://doi.org/10.1073/pnas.2015096118

Trevelline, B. K., Fontaine, S. S., Hartup, B. K., \& Kohl, K. D. (2019). Conservation biology needs a microbial renaissance: A call for the consideration of host-associated microbiota in wildlife management practices. Proceedings of the Royal Society B: Biological Sciences, 286(1895). https://doi.org/10.1098/rspb.2018.2448

Tung, J., Barreiro, L. B., Burns, M. B., Grenier, J. C., Lynch, J., Grieneisen, L. E., Altmann, J., Alberts, S. C., Blekhman, R., \& Archie, E. A. (2015). Social networks predict gut microbiome composition in wild baboons. ELife, 2015(4), 1-18. https://doi.org/10.7554/eLife.05224

Valentini, A., Pompanon, F., \& Taberlet, P. (2009). DNA barcoding for ecologists. Trends in Ecology and Evolution, 24(2), 110-117. https://doi.org/10.1016/j.tree.2008.09.011

van den Boogaart, K. G., \& Tolosana-Delgado, R. (2008). "Compositions": a unified R package to analyze compositional data. Computers \& Geosciences, 34(4), 320-338.

van der Hoek, Y., Binyinyi, E., Ngobobo, U., Stoinski, T. S., \& Caillaud, D. (2021). Daily travel distances of unhabituated Grauer's gorillas (Gorilla beringei graueri) in a low elevation forest. Folia Primatologica, 92(2), 112-125. https://doi.org/10.1159/000514626

van der Hoek, Y., Pazo, W. D., Binyinyi, E., Ngobobo, U., Stoinski, T. S., \& Caillaud, D. (2021). Diet of 

from faecal samples and museum-preserved specimens. Molecular Ecology Resources, 17(6), e111-e121. https://doi.org/10.1111/1755-0998.12699

van der Valk, T., Vezzi, F., Ormestad, M., Dalén, L., \& Guschanski, K. (2020). Index hopping on the Illumina HiseqX platform and its consequences for ancient DNA studies. Molecular Ecology Resources, 20(5), 1171-1181. https://doi.org/10.1111/1755-0998.13009

Watts, D. P. (1984). Composition and variability of mountain gorilla diets in the Central Virungas. American Journal of Primatology, 7(4), 323-356. https://doi.org/10.1002/ajp.1350070403

Weiss, S., Xu, Z. Z., Peddada, S., Amir, A., Bittinger, K., Gonzalez, A., Lozupone, C., Zaneveld, J. R., Vázquez-Baeza, Y., \& Birmingham, A. (2017). Normalization and microbial differential abundance strategies depend upon data characteristics. Microbiome, 5(1), 1-18.

West, A. G., Waite, D. W., Deines, P., Bourne, D. G., Digby, A., McKenzie, V. J., \& Taylor, M. W. (2019). The microbiome in threatened species conservation. Biological Conservation, 229 (November 2018), 85-98. https://doi.org/10.1016/j.biocon.2018.11.016

Wikberg, E. C., Christie, D., Sicotte, P., \& Ting, N. (2020). Interactions between social groups of colobus monkeys (Colobus vellerosus) explain similarities in their gut microbiomes. Animal Behaviour, 163, $17-$ 31. https://doi.org/10.1016/j.anbehav.2020.02.011

Yamagiwa, J., \& Basabose, A. K. (2006). Diet and seasonal changes in sympatric gorillas and chimpanzees at Kahuzi-Biega National Park. Primates, 47(1), 74-90. https://doi.org/10.1007/s10329-005-0147-7

Yamagiwa, J., Basabose, A. K., Kahekwa, J., Bikaba, D., Ando, C., Matsubara, M., Iwasaki, N., \& Sprague, D. S. (2013). Long-Term Research on Grauer's Gorillas in Kahuzi-Biega National Park, DRC: Life History, Foraging Strategies, and Ecological Differentiation from Sympatric Chimpanzees. In P. M. Kappeler \& D. P. Watts (Eds.), Long-Term Field Studies of Primates (pp. 1-460). Springer. https://doi.org/10.1007/9783-642-22514-7

Yamagiwa, J., Basabose, A. K., Kaleme, K., \& Yumoto, T. (2005). Diet of Grauer's gorillas in the montane forest of Kahuzi, Democratic Republic of Congo. International Journal of Primatology, 26(6), 13451373. https://doi.org/10.1007/s10764-005-8856-8

Yamagiwa, J., Mwanza, N., Yumoto, T., \& Maruhashi, T. (1991). Ant eating by eastern lowland gorillas. Primates, 32(2), 247-253. https://doi.org/10.1007/BF02381183

Yamagiwa, J., Mwanza, N., Yumoto, T., \& Maruhashi, T. (1994). Seasonal change in the composition of the diet of eastern lowland gorillas. Primates, 35(1), 1-14. https://doi.org/10.1007/BF02381481

Youngblut, N. D., Reischer, G. H., Walters, W., Schuster, N., Walzer, C., Stalder, G., Ley, R. E., \& Farnleitner, A. H. (2019). Host diet and evolutionary history explain different aspects of gut microbiome diversity among vertebrate clades. Nature Communications, 10(1), 1-15. https://doi.org/10.1038/s41467-01910191-3

Yumoto, T., Yamagiwa, J., Mwanza, N., \& Maruhashi, T. (1994). List of Plant Specles ldentified in KahuziBiega National Park, Zaïre. Tropics, 3(3/4), 295-308. 